Article

\title{
Dual Responsive Polymersomes for Gold Nanorod and Doxorubicin Encapsulation: Nanomaterials with Potential Use as Smart Drug Delivery Systems
}

\author{
Melissa DiazDuarte-Rodriguez ${ }^{1}$, Norma A. Cortez-Lemus ${ }^{1}$, Angel Licea-Claverie ${ }^{1, *(\mathbb{D} \text {, }}$ \\ Jacob Licea-Rodriguez ${ }^{2,3}$ and Eugenio R. Méndez ${ }^{2}$ \\ 1 Centro de Graduados e Investigación en Química. Tecnológico Nacional de México/Instituto Tecnológico de \\ Tijuana, A.P. 1166, C.P. 22000 Tijuana, B. C., México; melissa.duarte@tectijuana.edu.mx (M.D.-R.); \\ ncortez@tectijuana.mx (N.A.C.-L.) \\ 2 División de Física Aplicada. Centro de Investigación Científica y de Educación Superior de Ensenada, Carr. \\ Ensenada-Tijuana No. 3918, C.P. 22860 Ensenada, B. C., México; jlicea@cicese.mx (J.L.-R.); \\ emendez@cicese.mx (E.R.M.) \\ 3 Cátedras Conacyt, Centro de Investigación Científica y de Educación Superior de Ensenada, 22860 Ensenada, \\ B. C., México \\ * Correspondence: aliceac@tectijuana.mx; Tel.: +52-6646234043
}

Received: 23 April 2019; Accepted: 12 May 2019; Published: 30 May 2019

\begin{abstract}
In the present study, poly(ethylene glycol)-b-poly( $N, N$-diethylaminoethyl methacrylate) (PEG-b-PDEAEM) amphiphilic block copolymers were synthetized by reversible addition- fragmentation chain transfer (RAFT) polymerization using two different macro chain transfer agents containing PEG of 2000 and $5000 \mathrm{~g} / \mathrm{mol}$ and varying the length of the PDEAEM segment. From the obtained block copolymers, polymersome type nanometric aggregates were obtained by two different techniques. By direct dispersion, particle diameters around $200 \mathrm{~nm}$ were obtained, while by solvent exchange using THF and water, the obtained diameters were around $100 \mathrm{~nm}$. These block copolymers were used to encapsulate gold nanorods and doxorubicin (DOX) with good efficiencies to obtain nanomaterials with potential use as dual stimuli-sensitive drug delivery systems for combined anticancer therapies. Drug delivery studies showed that the release rate of DOX was accelerated when the $\mathrm{pH}$ was lowered from 7.4 to 5.8 and also when the systems were irradiated with a NIR laser at pH 7.4. The combination of lower $\mathrm{pH}$ and near infrared (NIR) irradiation resulted in higher drug release only in the case of polymersomes with lower molecular weight PEG.
\end{abstract}

Keywords: Block copolymers; stimuli sensitive polymers; gold nanorods; photothermal therapy; drug delivery systems; polymersomes

\section{Introduction}

In aqueous environments, amphiphilic block polymers have the ability to self-assemble into a variety of polymeric aggregates; the most common cases are micelles, where the hydrophobic blocks of the copolymer form the core while the hydrophilic blocks form the outer shell [1-3]. Larger, but still nanometric aggregates, such as polymersomes, are self-assembled hollow vesicles surrounded by amphiphilic block copolymer membranes that can be formed by bilayers or complex interdigitated structures [4]. Currently, there is a great deal of interest on polymersomes because of their structural analogies with living organelles and liposomes, and their potential applications as nanosized reactors and drug delivery systems [5,6] among others [7]. Block copolymer polymersomes have revealed to be promising alternatives to phospholipid-based vesicles regarding their stealthiness [3], improved stability, and ease of functionalization. Using the versatility of polymer chemistry, various 
polymersomes have been designed to combine features required for drug delivery applications, such as biodegradability, ability to load hydrophilic and hydrophobic drugs, and responsiveness to biologically relevant stimuli ( $\mathrm{pH}$ and temperature, among others) [8].

There are generally three main strategies to form polymersomes: To start from the bulk material in contact with water to form the final structures [9] (a "top down" approach), a "bottom up" approach starting from a completely dissolved amphiphilic block copolymer and then triggering the self-assembly process (nanoprecipitation or solvent displacement), and the formation of polymersomes during the polymerization or polymerization-induced self-assembly (PISA) process [10,11]. Among the mentioned techniques, solvent displacement is a reliable method which gathered reproducibility and control of particle size in a short time. Due to its versatility, this procedure can be applicable to a wide variety of polymers when suitable combinations of solvents are chosen [12]. For biomedical applications, the availability of stimuli-sensitive micelles or polymersomes able to control the release of drugs as a response to a slight change in $\mathrm{pH}$ or temperature is an appealing strategy. One class of potential candidates as both, $\mathrm{pH}$ - and temperature, responsive polymers, are the poly(tertiary amine-methacrylates), such as poly( $N, N$-diethylaminoethyl methacrylate) (PDEAEM) [13-17]. These polymers can be blockcopolymerized with a second, hydrophilic or hydrophobic polymer, to form the desired stimuli-sensitive polymer aggregates. In a previous study of our research group [17], poly(ethylene glycol)- $b$-poly( $N, N$-diethylaminoethyl methacrylate) $\left(\mathrm{PEG}_{47}-b\right.$-PDEAEM $\left.\mathrm{m}\right)$ copolymers were synthesized by reversible addition-fragmentation chain transfer (RAFT) polymerization. Direct dispersion in water of the diblocks resulted in polymersomes with sizes around $100 \mathrm{~nm}$, depending on the lengths of the PDEAEM segment as well as the $\mathrm{pH}$ of the solution. These materials were used as nanoreactors for the preparation of gold nanoparticles (AuNPs) in aqueous medium. One limitation of these materials was that only spherical AuNPs could be obtained and PDEAEM contents higher than $60 \%$ required long agitation periods for aggregate preparation and generated bimodal distributions of aggregates.

On the other hand, light-sensitive nanomaterials have recently received increasing attention for biomedical applications: photothermal therapy, photodynamic therapy and light-triggered drug delivery systems are being developed due to the high specificity and the non-invasive and low toxicity nature of the light stimulus [18-21]. Gold nanorods (AuNRs), similarly to gold nanoshells, nanostars and nanocages, show structure-dependent optical properties, with a tunable photothermal response to light [22]. In the particular case of AuNRs, two absorption bands, the transverse and longitudinal modes of the localized surface plasmon resonance (LSPR), can be observed in a typical UV/Vis absorbance spectrum; one appears at $520 \mathrm{~nm}$, while the other can be tuned within the visible or near infrared (NIR) spectrum, through the aspect ratio (length divided by diameter) of the nanorod. This distinctive optical characteristic, combined with other properties such as biocompatibility and facile surface functionalization, opens up several possibilities for fascinating applications of AuNRs in the biomedical field [23-27]. One of the main challenges for the application of AuNRs in therapy is their proper stabilization and selective delivery to goal cells. Methods tested include their surface functionalization $[28,29]$ and encapsulation with polymers using layer-by-layer techniques [30] and thiol groups [24]. Their encapsulation in micelles [25] and specially polymersomes [23] has been scarcely studied.

For the present study, gold nanorods with two different aspect ratios were synthesized by seed-mediated growth methods. They were encapsulated later with PEG-b-PDEAEM block copolymers synthesized by RAFT polymerization with macro chain transfer agents of 51 and 122 poly(ethylene glycol) repetitive units. The obtained polymersomes, containing gold nanorods and doxorubicin, were tested for their potential use as nanometric photothermal agents and drug delivery systems. The polymersomes are able to release their content as a response to changes in the $\mathrm{pH}$ of the environment, and also in response to temperature changes induced by the absorption of NIR laser light by the nanorods. 


\section{Materials and Methods}

\subsection{Materials}

The monomer $\mathrm{N}, \mathrm{N}$-diethylaminoethyl methacrylate (DEAEM, Sigma-Aldrich, Toluca, México) was distilled under reduced pressure before use. Tetrachloroauric acid trihydrate $\left(\mathrm{HAuCl}_{4} \cdot 3 \mathrm{H}_{2} \mathrm{O}\right)$, hexadecyltrimethyl-ammonium bromide $(\mathrm{CTAB})$, ascorbic acid, silver nitrate $\left(\mathrm{AgNO}_{3}\right)$, sodium borohydride $\left(\mathrm{NaBH}_{4}\right)$, methoxy-poly(ethylene glycol) $\left(\mathrm{M}_{\mathrm{n}}=2000 \mathrm{~g} / \mathrm{mol}\right.$ and $\left.\mathrm{M}_{\mathrm{n}}=5000 \mathrm{~g} / \mathrm{mol}\right)$, p-dioxane (anhydrous), 4-dimethylamino pyridine (DMAP), 4,4-azobis(4-cyanovaleric acid) (ACVA), doxorubicin hydrochloride (DOX), and $N, N^{\prime}$-dicyclohexylcarbodiimide (DCC) were purchased from Sigma-Aldrich, Toluca, México, and used as received. The following solvents were provided by FERMONT, Monterrey, México, and used as received: dichloromethane (DCM), tetrahydrofurane (THF), dimethyl sulfoxide (DMSO), toluene, diethylether and petroleum ether. Purification of synthetic products by column chromatography was performed using silica gel (70-230 mesh, Acros Organics, Geel, Belgium).

\subsubsection{Macro Chain Transfer Agent (macroCTA) Synthesis}

Two different macro chain agents were synthetized using methoxy-poly(ethylene glycol) with different molecular weights $\left(\mathrm{M}_{n}\right)$. Their $\mathrm{M}_{\mathrm{n}}$ and repetitive unit number $(\mathrm{n})$ were previously confirmed by ${ }^{1} \mathrm{H}-\mathrm{NMR}$ analysis, which are available in the Supplementary Materials file: $\mathrm{M}_{\mathrm{n}}=2276 \mathrm{~g} / \mathrm{mol}$, $\mathrm{n}=51 ; \mathrm{M}_{\mathrm{n}}=5400 \mathrm{~g} / \mathrm{mol}, \mathrm{n}=122$, (Figure S1). The synthesis of the PEG51-macroCTA was conducted as previously reported in the literature [17]. For the synthesis of the $\mathrm{PEG}_{122}$-macroCTA, the same synthetic protocol was adapted; details are described in the Supplementary Materials file, and their ${ }^{1} \mathrm{H}-\mathrm{NMR}$ spectra are also shown (Figure S2).

\subsubsection{Synthesis of Block Copolymers PEG-b-PDEAEM}

The synthesis of the block copolymers was carried out as described in the literature [17]. For the present work, a series of block copolymers was prepared by using different ratios of $\mathrm{N}, \mathrm{N}$-(diethylamino)ethyl methacrylate (DEAEM) and the $\mathrm{PEG}_{51}$ - or $\mathrm{PEG}_{122}$-macroCTAs. The synthesis of the block copolymer PEG $_{122}-b$-PDEAEM 96 is briefly described: DEAEM (1.0 g, $\left.5.4 \mathrm{mmol}\right)$, $\mathrm{PEG}_{122}$-macroCTA $(0.2702 \mathrm{~g}, 0.05 \mathrm{mmol})$ and 4,4-azobis-4-cyanovaleric acid $(0.0035 \mathrm{~g}, 0.0125 \mathrm{mmol})$ were dissolved in $4 \mathrm{~mL}$ of $p$-dioxane and mixed in a glass vial. This mixture was transferred to an ampoule. Oxygen was removed using three freeze (under Nitrogen) -thaw (under vacuum) evacuation cycles, and the ampoule was sealed with a propane torch flame under vacuum. The solution was heated to $70{ }^{\circ} \mathrm{C}$ in a mineral oil bath with magnetic stirring. At designated times $(24,36$ or $48 \mathrm{~h}$ ), the polymerization was stopped by cooling to room temperature. Then, the polymer solution was concentrated with a rotary evaporator. The mixture was dissolved with the minimum amount of DCM and precipitated with $15 \mathrm{~mL}$ of petroleum ether (x3). Then, the polymer was dissolved with a 2:5 DCM:ethanol solvent mixture and stirred for $30 \mathrm{~min}$; later, $12 \mathrm{~mL}$ of cold diethyl ether was added and the sample was left undisturbed for $24 \mathrm{~h}$. The white precipitate was discarded and the yellow liquid concentrated with a rotary evaporator. The final product was dried in a vacuum oven at $35^{\circ} \mathrm{C}$ for $24 \mathrm{~h}$. Polymerization yields were determined using the gravimetric method; in this case, $43.7 \%$ yield was obtained.

$\mathrm{PEG}_{122}$ - $b$-PDEAEM ${ }_{96} ; \mathrm{M}_{\mathrm{n}}(\mathrm{GPC})=28082 \mathrm{~g} / \mathrm{mol}, \mathrm{Ð}=1.22{ }^{1} \mathrm{H}-\mathrm{NMR}\left(400 \mathrm{MHz}, \mathrm{CDCl}_{3}, \delta, \mathrm{ppm}\right):$ $3.99\left(\mathrm{OCOCH}_{2} \mathrm{CH}_{2} \mathrm{~N}\right), 3.64\left(\mathrm{CH}_{2} \mathrm{CH}_{2} \mathrm{O}\right.$ of the PEG chain), 2.69-2.57 $\left(\mathrm{OCOCH}_{2} \mathrm{CH}_{2} \mathrm{NCH}_{2}\right), 3.38\left(\mathrm{OCH}_{3}\right.$, chain end of the PEG), 1.81 ( $\mathrm{CH}_{2}$ of the polymer backbone), 1.25 (aliphatic chain of the CTA), 1.17-0.9 $\left(\mathrm{CH}_{3}\right.$ of the polymer backbone and $\left.\mathrm{NCH}_{2} \mathrm{CH}_{3}\right)$.

\subsubsection{Preparation of Nanometric Polymer Aggregates}

For the preparation of the copolymer aggregates in this work, two different methodologies were used: direct dispersion in distilled water and solvent displacement or nanoprecipitation using 
THF/water. Direct dissolution: Consist of the solubilization of the bulk copolymer PEG $_{m}-b$-PDEAEM $(5 \mathrm{mg})$ in distilled water $(10 \mathrm{~mL})$ under magnetic stirring at $25^{\circ} \mathrm{C}$ for $48 \mathrm{~h}$.

Solvent displacement or nanoprecipitation: At first, $5 \mathrm{mg}$ of the copolymer was dissolved in $1 \mathrm{~mL}$ of THF, then, $10 \mathrm{~mL}$ of distilled water was added dropwise to the copolymer solution under magnetic stirring. The copolymer solution was stirred in an open container for $24 \mathrm{~h}$ inside an extraction hood to remove the THF, allowing polymer aggregate formation.

\subsubsection{Gold Nanorod Synthesis}

The AuNR synthesis was performed based on a previously reported methodology [24]. First, CTAB-coated gold seeds were prepared by chemical reduction of $\mathrm{HAuCl}_{4}$ using $\mathrm{NaBH}_{4}$. In a typical procedure, $0.25 \mathrm{~mL}$ of $\mathrm{HAuCl}_{4}$ solution $(10 \mathrm{mM})$ was mixed with $7.5 \mathrm{~mL}$ of CTAB solution $(100 \mathrm{mM})$ in a $20 \mathrm{~mL}$ vial under stirring. Then, $0.6 \mathrm{~mL}$ of ice-cold $\mathrm{NaBH}_{4}$ solution $(10 \mathrm{mM})$ was injected quickly under vigorous stirring; immediately the solution turned brown-yellow, suggesting the formation of gold seeds. The gold seed dispersion was stored for 2 or $8 \mathrm{~h}$ before further use to allow the decomposition of excess $\mathrm{NaBH}_{4}$. Second, the AuNRs were prepared from gold seeds within a growth solution. Specifically, a growth solution containing $100 \mathrm{~mL}$ of CTAB solution $(100 \mathrm{mM}), 5 \mathrm{~mL}$ of $\mathrm{HAuCl}_{4}$ solution $(10 \mathrm{mM}), 1 \mathrm{~mL}$ of $\mathrm{AgNO}_{3}$ solution $(10 \mathrm{mM})$, and $1 \mathrm{~mL}$ of $\mathrm{H}_{2} \mathrm{SO}_{4}(1 \mathrm{M})$ was poured into a $250-\mathrm{mL}$ round-bottom flask and equilibrated at $30^{\circ} \mathrm{C}$ under stirring for $30 \mathrm{~min}$, and then, $0.8 \mathrm{~mL}$ of an ascorbic acid solution $(100 \mathrm{mM})$ was injected quickly under vigorous stirring; immediately the solution became colorless. Then, $250 \mathrm{~mL}$ of gold seed dispersion from the first step was added under vigorous stirring for $2 \mathrm{~min}$ and left undisturbed for $6 \mathrm{~h}$; the solution turned violet-blue. The prepared AuNRs were purified via centrifugation (12,000 rpm for $15 \mathrm{~min}$ ) followed by dispersion in $40 \mathrm{~mL}$ of de-ionized water. This purification step was repeated three times.

\subsubsection{Gold Nanorod Encapsulation}

Two sizes of gold nanorods were coated using polymersomes: AuNR-846 and AuNR-761. For this, $2 \mathrm{~mL}$ of a $\mathrm{PEG}_{\mathrm{m}}-b$-PDEAEM $\mathrm{n}$ block copolymer solution $(10 \mathrm{mg} / \mathrm{mL})$ in DMSO was added dropwise to a AuNRs dispersion in water $(10.0 \mathrm{~mL}, 0.18 \mathrm{mg} / \mathrm{mL})$ under strong stirring. After $48 \mathrm{~h}$ under stirring, the dispersion was centrifuged and washed with water $(14,000 \mathrm{rpm}, 12 \mathrm{~min})$ to remove excess polymer (supernatant) and then dialyzed against deionized water to remove the excess of DMSO using a 12 KDa MWCO dialysis bag from SpectraPor ${ }^{\circledR}$ (four water changes every $30 \mathrm{~min}$ and then four changes every hour). Unloaded AuNRs precipitate inside the dialysis-bag, while encapsulated/stabilized gold nanorods were removed and quickly frozen in a acetone/dry ice bath $\left(\sim-70^{\circ} \mathrm{C}\right)$. The polymersome-coated gold nanoparticles were then freeze-dried to characterize the obtained PEG $_{m}-b$-PDEAEM ${ }_{n} @ A u N R s$ by different methodologies. The AuNR loading content $\left(\mathrm{LC}_{\mathrm{AuNR}}\right)$ was determined by thermogravimetric analysis (TGA), subtracting the residue after measurement of the plain blockcopolymers from the residue of the AuNR loaded polymersomes. The AuNR loading efficiency $\left(L E_{A u N R}\right)$ was estimated by the mass ratio of the loaded AuNR in each polymersome to the mass of AuNR in the loading solution used.

\subsection{Measurements}

Hydrogen nuclear magnetic resonance ( $\left.{ }^{1} \mathrm{H}-\mathrm{NMR}\right)$ spectra were collected on a Bruker AMX-400 (Bruker Corporation, Billerica MA, USA) (400 MHz) spectrometer and are reported in ppm using tetramethylsilane (TMS) as the internal standard. The solvent used was deuterated chloroform, $\mathrm{CDCl}_{3}$, for all samples.

Gel permeation chromatography (GPC) was performed on a Viscotek 305 TDA chromatograph, (Malvern, Worcestershire, United Kingdom) equipped with two T-columns in series (CLM3009: styrene divinylbenzene copolymer) and five detectors: refractive index (RI), viscosity (VISC-DP), UV-PDA and light scattering (RALS and LALS). The measurements were performed in THF at $35^{\circ} \mathrm{C}$. The conversion of the monomers to the polymer was determined by gravimetric method. 
Thermogravimetric analysis (TGA) was performed on a TA-Instruments Discovery-TGA equipment (TA-Instruments, New Castle DE, USA). Measurements were performed for blockcopolymers and AuNR loaded polymer aggregates by heating under nitrogen flow from room temperature up to $600{ }^{\circ} \mathrm{C}$ at a heating rate of $10^{\circ} \mathrm{C} / \mathrm{min}$.

Dynamic light scattering (DLS) measurements were carried out in $0.5 \mathrm{mg} / \mathrm{mL}$ block copolymer solutions at $25{ }^{\circ} \mathrm{C}$ using a Malvern Instruments Nano-ZS Nanosizer (ZEN 3690), (Malvern, Worcestershire, UK). The instrument is equipped with a helium neon laser $(633 \mathrm{~nm})$ with size detection between $0.6 \mathrm{~nm}$ and $5 \mu \mathrm{m}$. DLS experiments were performed at the scattering angle of $90^{\circ}$ and the distribution of sizes was calculated using Malvern Instruments dispersion technology software, based on CONTIN analysis and Stokes-Einstein equation for spheres as usual.

UV-Vis spectra were acquired by using a UV-Vis Varian Cary 100 spectrophotometer system (Agilent Technologies, Santa Clara, CA, USA) at room temperature on AuNPs dispersions for the measurement of the localized surface plasmon resonance. In the cases where the localized surface plasmon resonance was found at higher wavelengths than $900 \mathrm{~nm}$, an UV-Vis-NIR Varian Cary 5000 spectrophotometer was used for measurements in wavelengths up to $1000 \mathrm{~nm}$.

Atomic Force Microscopy (AFM) characterization of the aggregates was performed by means of a SPM 5100 atomic force microscope (Agilent Technologies, Santa Clara, CA, USA) in intermittent mode using silicon cantilevers in the $145 \mathrm{KHz}$ to $160 \mathrm{KHz}$ frequency range using amplitudes of 3 to $5 \mathrm{~V}$. The scanner (N9520A) operation interval was $10 \mu \mathrm{m} \times 10 \mu \mathrm{m}$. Samples were prepared using concentrations of $0.05 \mathrm{mg} / \mathrm{mL}$ of the copolymers in distilled water, and a drop was placed over a mica substrate at $25{ }^{\circ} \mathrm{C}$. Images were edited using the WSxM Develop 3.0 software from electronic nanotechnology.

Scanning electron microscope micrographs were acquired by analytical field emission scanning electron microscope (FESEM) Jeol model JSM-7800F Prime (JEOL Ltd, Tokyo, Japan). The images were acquired in the scanning transmission electron microscopy (STEM) mode, using a bright field (BF) and a high angle annular dark field (HAADF) detector working at $25 \mathrm{kV}$. Samples were prepared by dispersing $0.5 \mathrm{mg}$ of samples in $10 \mathrm{~mL}$ of water under stirring for $48 \mathrm{~h}$. A drop of those dispersions was poured over a 300-mesh lacy carbon copper grid followed by drying in air at room temperature. Diameter and Length distribution histograms were plotted from measurements of AuNRs one by one from the FESEM images.

Transmission electron microscopy micrographs (TEM) were acquired by using a H7500 transmission electron microscope (Hitachi Co. Ltd., Tokyo, Japan) operating at an accelerating voltage of $80 \mathrm{kV}$. Samples were prepared by dispersing $0.5 \mathrm{mg}$ of blockopolymers in $1 \mathrm{~mL}$ of water under stirring for $48 \mathrm{~h}$. A drop of those dispersions was poured over a 75-mesh copper grid coated with a thin layer of carbon followed by removing excess liquid at room temperature. Afterwards, the samples were stained using a $1 \%$ uranyl acetate solution for $1 \mathrm{~min}$. Diameter distribution histograms were plotted from measurements of one representative TEM image for each sample applying a Gaussian fit.

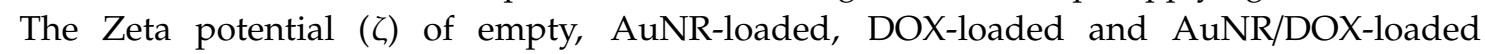
polymersomes dispersion $(0.5 \mathrm{mg} / \mathrm{mL}$ ) were measured using a Malvern ZetaSizer Nano ZS instrument (Malvern, Worcestershire, UK). All the measurements were the average of three runs and performed at $25^{\circ} \mathrm{C}$ and $\mathrm{pH}=7.4$ (only the empty polymersomes were measured at different $\mathrm{pH}$ values to estimate their isoelectric point).

\subsubsection{NIR Induced Heating Studies}

The first light-induced heating studies of the AuNR-loaded polymersomes aqueous suspension were performed with a diode laser ( $808 \mathrm{~nm}$, Oclaro Inc., San Jose, CA, USA) with a maximum output power of $450 \mathrm{~mW}$. A 1.5-mL Eppendorf tube was filled with the $\mathrm{PEG}_{\mathrm{m}}-b-\mathrm{PDEAEM}_{\mathrm{n}} @ \mathrm{AuNR}_{\mathrm{u}}$ aqueous suspension with a concentration of $0.25 \mathrm{mg} / \mathrm{mL}$, and then fixed inside a foam fixture. The evolution of temperatures due to the laser irradiation of the aqueous suspension was monitored with a thermocouple, placed $1 \mathrm{~cm}$ below the liquid surface. A plain water sample was irradiated under the same conditions 
and was used as control. For the second irradiation study series, a Titanium-Sapphire laser oscillator (Griffin, KMLabs Inc., Boulder, CO, USA) operating at $808 \mathrm{~nm}$ in the continuous-wave mode (cw) was used, in this case the output laser power was varied from 100 to $200 \mathrm{~mW}$.

\subsubsection{Loading of Doxorubicin}

Based on the methodology reported by Lecommandoux [31], for a DOX/copolymer ratio of 0.3/1 on the feed, $10 \mathrm{mg}$ of block copolymers and $3 \mathrm{mg}$ of DOX were dissolved on $1 \mathrm{~mL}$ of DMSO, then PBS at $\mathrm{pH} 7.4$ was added and left under magnetic stirring for $48 \mathrm{~h}$. The excess of DOX and DMSO were removed by dialysis against distilled water $\left(500 \mathrm{~mL}\right.$, SpectraPor ${ }^{\circledR}$ dialysis tubing MWCO 12-14 KDa); the external medium was renewed every $30 \mathrm{~min}$ for $2 \mathrm{~h}$ and then every hour for $4 \mathrm{~h}$ giving a total of eight water changes. The purified material was quickly frozen using an acetone/dry ice bath $\left(\sim-70^{\circ} \mathrm{C}\right)$ to keep the formation of ice-crystals small and then freeze-dried. The mass of DOX loaded in the polymersomes was determined by preparing a $0.5-\mathrm{mg} / \mathrm{mL}$ solution in DMSO, measuring the absorbance by UV analysis at $\lambda_{\max }=484 \mathrm{~nm}$ and then quantified by using a calibration curve of DOX in DMSO (Figure S3 in Supplementary Materials file). To obtain polymersomes loaded with DOX and AuNR, the same methodology was used with the only difference that AuNR purified solution was added to the DOX/copolymer in DMSO dispersion. The loading efficiency of DOX (DLE $E_{\mathrm{DOX}}$ ) and the loaded DOX content ( $\mathrm{DLC}_{\mathrm{DOX}}$ ) were calculated using the following simple equations:

$$
\begin{gathered}
\mathrm{DLE}_{\mathrm{DOX}}=(\text { mass of DOX in polymersomes }) /(\text { mass of DOX in loading solution }) \\
\mathrm{DLC}_{\mathrm{DOX}}=(\text { mass of DOX in polymersomes }) /(\text { mass of dry polymer })
\end{gathered}
$$

\subsubsection{In vitro release studies}

For the controlled release studies, $1.5 \mathrm{mg}$ of DOX loaded material was dispersed in $3 \mathrm{~mL}$ of buffer solution ( $\mathrm{pH} 7.4$ or 5.8) and then added to a dialysis tube (Spectra/Por ${ }^{\circledR}$ MWCO: 1000 Da, diameter $10 \mathrm{~mm}$, from Spectrum, Los Angeles, CA, USA). The dialysis tube was introduced into $50 \mathrm{~mL}$ of release medium inside an Erlenmeyer flask. The flask was poured inside a shaking bath (Shel Lab, model SWBR17, Sheldon Manufacturing, Inc., Cornelius, OR, USA) operating at $37^{\circ} \mathrm{C}$ and at a shaking speed of $70 \mathrm{rpm}$. Three $\mathrm{mL}$ aliquots of the medium were taken out at different times and replaced by $3 \mathrm{~mL}$ of fresh PBS at every sampling point. The released fraction of DOX was calculated from UV measurements at $\lambda_{\max }=484 \mathrm{~nm}$ and then quantified by using a calibration curve of DOX in PBS (Figure S4 in Supplementary Materials file).

For the NIR-triggered release studies, the same methodology was followed, with the exception that the dialysis tube containing the DOX-loaded PEG $\mathrm{m}-b-\mathrm{PDEAEM}_{\mathrm{n}} @ A$ AuNRs was irradiated from the top every hour for $5 \mathrm{~min}$ during the first $10 \mathrm{~h}$ of the study.

\section{Results and Discussion}

\subsection{Synthesis and Characterization of PEG-b-PDEAEM Block Copolymers}

Block copolymers that contain polyethylene glycol of nominal molecular weights of 2000 and $5000 \mathrm{~g} / \mathrm{mol}\left(\mathrm{PEG}_{51}\right.$ or $\mathrm{PEG}_{122}$ ) as the hydrophilic part, and PDEAEM as the $\mathrm{pH}$-dependent hydrophobic part, in a proportion which allows the copolymer to be water dispersible, were prepared (Figure 1). Due to its hydrophobic characteristics, long segments of PDEAEM in the block copolymer do not allow the formation of stable aggregates in aqueous solution at neutral $\mathrm{pH}$. From the literature [17],

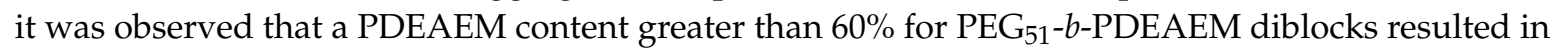
diblocks hard to be dispersed in water and unstable aggregates that tend to precipitate. Therefore, in this investigation a series of block copolymers of different molecular weights and PDEAEM content lower than $50 \%$ were prepared by RAFT polymerization. 
<smiles>COCCOC(=O)CCC(C)(N)SC(=S)Sc1ccc(C(C)(C)C)c(C(C)(C)C)c1</smiles>

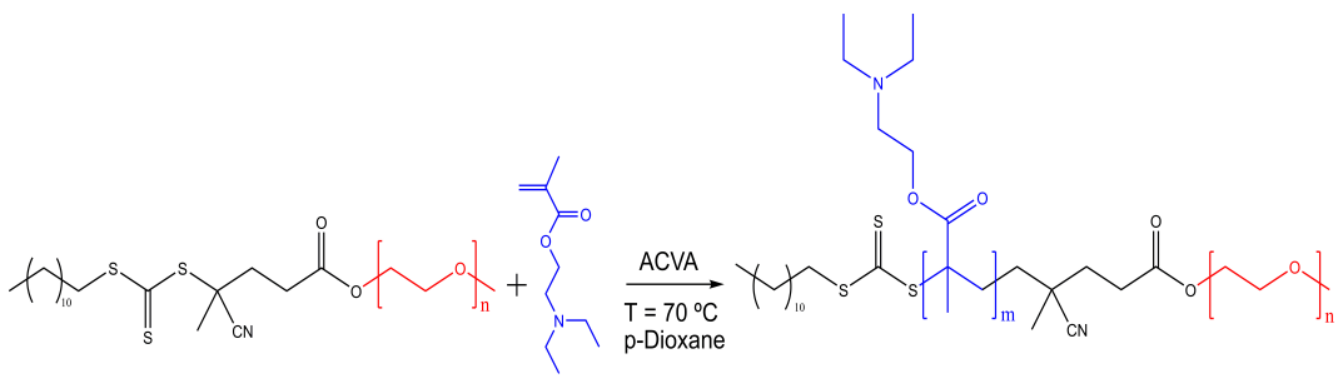

$$
\mathrm{n}=\mathrm{PEG} \text { units }(51 \text { or } 122)
$$
$m=$ PDEAEM units

Figure 1. Synthetic scheme for the preparation of PEG-b-PDEAEM block copolymers by RAFT polymerization.

Table 1 shows a summary of the synthesized block copolymers. Blocks between 11,200 to 23,700 g/mol were prepared with PDEAEM contents ranging from 31 to $48 \%$. The molecular weight for the copolymers was determined initially by GPC using a dn/dc value of 0.087 for PDEAEM in THF as reported in the literature [32]. All the prepared copolymers showed acceptable dispersity (Đ) values for a RAFT polymerization. However, in some cases, particularly for the copolymer PEG $_{51}-b$-PDEAEM 47 $\left(\mathrm{P}_{51} \mathrm{D}_{47}\right)$, there were discrepancies between the molecular weight calculated with the RAFT equation (see Equation (3) below) and the one estimated by GPC.

Table 1. RAFT polymerization of DEAEM in p-dioxane at $70{ }^{\circ} \mathrm{C}$ for $48 \mathrm{~h}$ using $\mathrm{PEG}_{51}$ - and PEG $_{122}$-macroCTAs as RAFT agents.

\begin{tabular}{|c|c|c|c|c|c|c|c|}
\hline Sample ${ }^{a}$ & M:macroCTA:I & $\begin{array}{l}\text { Yield }^{b} \\
(\%)\end{array}$ & $\begin{array}{c}M_{\mathrm{n}(\mathrm{CALC})}{ }^{\mathrm{c}} \\
\left(\mathrm{g} \mathrm{mol}^{-1}\right)\end{array}$ & $\begin{array}{c}M_{\mathrm{n}(\mathrm{GPC})}{ }^{\mathrm{d}} \\
\left(\mathrm{g} \mathrm{mol}^{-1}\right)\end{array}$ & $\bigoplus^{d}$ & $\begin{array}{c}\mathrm{M}_{\mathrm{n}(\mathrm{NMR})} \mathrm{e} \\
\left(\mathrm{g} \mathrm{mol}^{-1}\right)\end{array}$ & $\begin{array}{c}\text { PEG:PDEAEM } \\
\text { (Molar ratio) }\end{array}$ \\
\hline $\mathrm{P}_{51} \mathrm{D}_{47}$ & $432: 8: 1$ & 51.7 & 12408 & 21020 & 1.11 & 11283 & 52: 48 \\
\hline $\mathrm{P}_{122} \mathrm{D}_{54}$ & $432: 6: 1^{f}$ & 38.9 & 19038 & 19619 & 1.35 & 15807 & 69: 31 \\
\hline $\mathrm{P}_{122} \mathrm{D}_{59}$ & $432: 4: 1^{\mathrm{f}}$ & 39.1 & 25708 & 24431 & 1.14 & 16734 & 67: 33 \\
\hline $\mathrm{P}_{122} \mathrm{D}_{87}$ & $432: 6: 1$ & 40.0 & 19038 & 23187 & 1.03 & 22047 & 58: 42 \\
\hline $\mathrm{P}_{122} \mathrm{D}_{96}$ & $432: 4: 1$ & 43.7 & 25708 & 28082 & 1.22 & 23715 & 56: 44 \\
\hline
\end{tabular}

${ }^{a}$ The subscript numbers represents the number of repeating units of each PEG (P) and PDEAEM (D) block estimated by using ${ }^{1} \mathrm{H}-\mathrm{NMR}(400 \mathrm{MHz}) ;^{\mathrm{b}}$ Determined by gravimetry; ${ }^{\mathrm{c}}$ Molecular weight calculated from the RAFT polymerization Equation (3) assuming a 100\% conversion; ${ }^{\mathrm{d}}$ Molecular weight and dispersity $\left(\mathrm{D}=\mathrm{M}_{\mathrm{W}} / \mathrm{M}_{\mathrm{n}}\right)$ values determined by GPC using dn/dc $=0.087 \mathrm{~mL} / \mathrm{g}$ [33]; ${ }^{\text {e }}$ Determined by $1 \mathrm{H}$ NMR (400 MHz); ${ }^{\mathrm{f}}$ Polymerized for $36 \mathrm{~h}$.

This can be attributed to the fact that the $\mathrm{dn} / \mathrm{dc}$ value used for the $\mathrm{M}_{\mathrm{n}}(\mathrm{GPC})$ calculation was not appropriate for the block copolymer. Equation (3) follows:

$$
M n_{(\text {Calc })}=\left[\left(\frac{[M]}{[C T A]}\right) x M_{0} x \text { Conv. }\right]+M W_{C T A}
$$

where $[M]$ is the monomer concentration, $[C T A]$ is the CTA concentration, $M_{o}$ is the molecular weight of the monomer, Conv. is the gravimetric conversion, and $M W_{C T A}$ is the molecular weight of the CTA used. GPC traces for the analyzed copolymers can be observed in the Supplementary Materials file (Figure S5).

The molecular weight was also obtained by ${ }^{1} \mathrm{H}-\mathrm{NMR}$ calculating the number of repetitive units of DEAEM from the integration value of the signal $\mathrm{CH}_{2}-\mathrm{O}$ at $4.0 \mathrm{ppm}$ in relation with the signal at 3.38 ppm corresponding to the methoxy end group of the PEG-CTA (Figure S6). Results are 
included in Table 1 and show that in the majority of cases there is a better agreement between these values and the theoretical values as calculated using the RAFT Equation (3). The true composition of the block copolymers was also determined by ${ }^{1} \mathrm{H}-\mathrm{NMR}$. In Figure 2, the ${ }^{1} \mathrm{H}-\mathrm{NMR}$ spectrum of the $\mathrm{PEG}_{122}$-b-PDEAEM 96 copolymer is shown as an example; the following signals were observed: strong signals between 1.04 and $0.9 \mathrm{ppm}$ were attributed to methyl groups of the PDEAEM segment " $\mathrm{f}$ " and " $\mathrm{a}$ "; a signal at 1.81 ppm corresponded to the methylene group in the PDEAEM backbone " $\mathrm{b}$ "; multiple signals in chemical shifts between 2.69 and $2.57 \mathrm{ppm}$ correspond to the methylene groups next to the nitrogen atom " $\mathrm{d}$ " and " $\mathrm{e}$ "; a singlet at $3.38 \mathrm{ppm}$ corresponds to the methoxy terminal group of the PEG " $\mathrm{i}$ "; a signal at 3.64 ppm corresponds to the methylene groups in the PEG repetitive units " $\mathrm{h}$ "; and a signal at $4.0 \mathrm{ppm}$ was attributed to the methylene group next to the oxygen atom in PDEAEM " $\mathrm{c}$ ". A signal that can be attributed to the CTA can be observed at $1.25 \mathrm{ppm}$ corresponding to the aliphatic chain (ten $\mathrm{CH}_{2}$ units). For this particular block copolymer, the true composition is $44 \%$ DEAEM and 56\% EG units as calculated using the integration of the methylene groups in the PEG repetitive units at $3.64 \mathrm{ppm}$ in relation to the integration of the signal at $4.0 \mathrm{ppm}$ corresponding to the DEAEM methylene group next to oxygen. The NMR spectra for the other block copolymers can be found in the Supplementary material file (Figure S6).

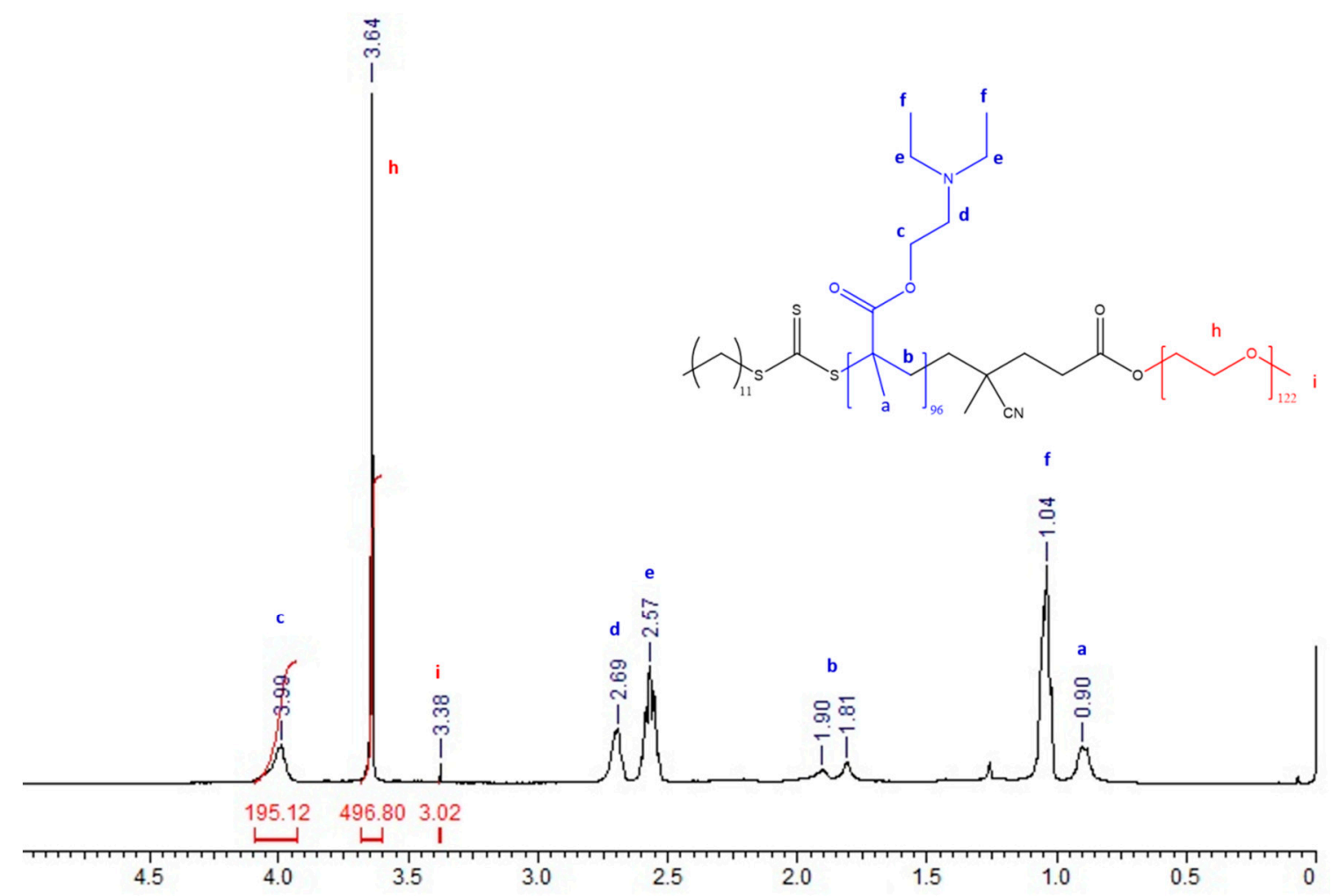

Figure 2. ${ }^{1} \mathrm{H}-\mathrm{NMR}\left(400 \mathrm{~Hz}, \mathrm{CDCl}_{3}\right)$ spectra for the block copolymer $\mathrm{PEG}_{122}-b$-PDEAEM 96 .

\subsection{Self-assembly Studies of the PEG-b-PDEAEM Copolymers}

Dynamic light scattering measurements were performed on the polymer aggregates obtained from the synthetized copolymers in water using two different preparation techniques. For the copolymer aggregates prepared by direct dispersion of the block copolymers in distilled water, all the solutions were mixed under magnetic stirring for $48 \mathrm{~h}$ before the analysis. All the copolymers were dispersible at concentrations of $0.5 \mathrm{mg} / \mathrm{mL}$ or lower and the $\mathrm{pH}$ of the solutions prior to the DLS analysis was between 7.4 and 7.7 depending on the PDEAEM content of the copolymer. Considering that the $\mathrm{pK}_{\mathrm{a}}$ of the PDEAEM is 7.4 [33], at these $\mathrm{pH}$ values, the amine groups in the PDEAEM segments of the copolymer are only partially protonated, rendering the PDEAEM segment hydrophobic behavior, and allowing the possible formation of aggregates stabilized by the hydrophilic PEG segments. As observed in 
Figure $3 a$, all the copolymers exhibited monomodal distributions of sizes with hydrodynamic diameters of around $200 \mathrm{~nm}$ and polydispersities of around 0.3. In the case of aggregates obtained by solvent exchange, lower sizes and narrower distributions of sizes were observed. This may result from the fact that the amphiphilic copolymers are first homogeneously dissolved in THF and subsequently mixed with water, allowing the formation of a more stable and compact membrane for the newly formed polymeric vesicles (polymersomes) as compared to the ones obtained by direct dispersion in water of the strong hydrophobic block copolymers. The size distributions for the copolymer aggregates obtained by solvent exchange are shown in Figure $3 b$.
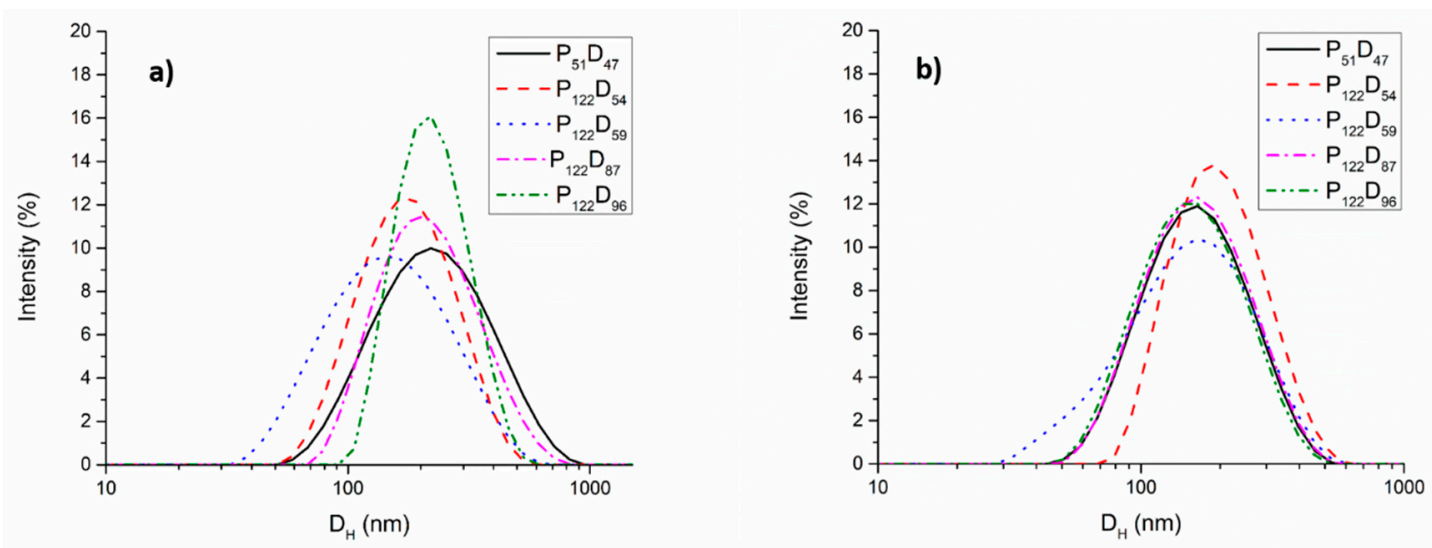

Figure 3. DLS distribution of sizes for the polymer aggregates obtained by: (a) direct dispersion in water, and (b) solvent exchange or nanoprecipitation.

In Table 2, a summary of the $\mathrm{D}_{\mathrm{H}}$ values for the polymer aggregates obtained by direct dispersion and solvent exchange, and the corresponding diameters (D) observed by AFM, are included. The extended chain lengths for the PEG- $b$-PDEAEM block copolymers were calculated for comparison purposes. For this, the number of units in the block copolymer were taken and a carbon-carbon extension in $\mathrm{SP}_{3}$ hybridization state for the extended PDEAEM segment (end to end distance $\left.<\mathrm{h}^{2}\right\rangle^{0.5}$ ) and the Flory approximation for the random coiled PDEAEM in tetha solvent, were considered as described previously [17]. For the PEG-block, using the reported value $<\mathrm{h}^{2}>^{0.5}=3.21 \pm 0.5 \mathrm{~nm}$ for a polyethylene oxide polymer of 36 units [34], a simple scaling to a PEG of 51 and 122 units results in $<\mathrm{h}^{2}>0.5$ values of $4.55 \mathrm{~nm}$ and $10.88 \mathrm{~nm}$ respectively. The end-to-end distance of the block copolymers studied range from $7.63 \mathrm{~nm}$ to $17.5 \mathrm{~nm}$ (coiled PDEAEM) to $16.14 \mathrm{~nm}$ to $35.26 \mathrm{~nm}$ (fully extended PDEAEM). Comparing these values with the $\mathrm{D}_{\mathrm{H}}$ observed by DLS, regardless of the preparation technique used for the copolymer aggregates, a double layer aggregate such as a polymersome morphology is suspected, since a simple spherical micelle would have a diameter of 15.3 to $32.3 \mathrm{~nm}$ for the $\mathrm{PEG}_{51}$ copolymer and of 29.3 to $70.5 \mathrm{~nm}$ for the $\mathrm{PEG}_{122}$ copolymers (two times the end-to-end distance of the polymer chains).

Table 2. Dynamic light scattering and microscopy analysis for polymer aggregates (sizes in $\mathrm{nm}$ ).

\begin{tabular}{|c|c|c|c|c|c|c|c|}
\hline Sample ${ }^{a}$ & PEG:PDEAEM ${ }^{\text {a }}$ & $\begin{array}{c}D_{H}(\text { direct } \\
\text { dispersion) }^{b}\end{array}$ & $\begin{array}{l}D_{H} \text { (solvent } \\
\text { exchange) } b\end{array}$ & D (AFM) & $\mathrm{D}^{\mathrm{c}}$ (TEM) & $\mathbf{n}_{\text {PDEAEM }}{ }^{a}$ & $L(n m)^{d}$ \\
\hline $\mathrm{P}_{51} \mathrm{D}_{47}$ & $52: 48$ & 208 & 100 & $109.3 \pm 13.8$ & $119.5 \pm 7.4$ & 46 & $7.63-16.14$ \\
\hline $\mathrm{P}_{122} \mathrm{D}_{54}$ & $69: 31$ & 197 & 150 & $206.7 \pm 26.5$ & $105 \pm 3.7$ & 54 & $14.65-24.59$ \\
\hline $\mathrm{P}_{122} \mathrm{D}_{59}$ & $67: 33$ & 140 & 180 & $163.3 \pm 42.7$ & - & 59 & $14.95-25.87$ \\
\hline $\mathrm{P}_{122} \mathrm{D}_{87}$ & $58: 42$ & 217 & 120 & $122.0 \pm 18.6$ & - & 87 & $16.88-32.98$ \\
\hline $\mathrm{P}_{122} \mathrm{D}_{96}$ & $56: 44$ & 238 & 115 & $173.4 \pm 44.0$ & $137.6 \pm 9.6$ & 96 & $17.50-35.26$ \\
\hline
\end{tabular}

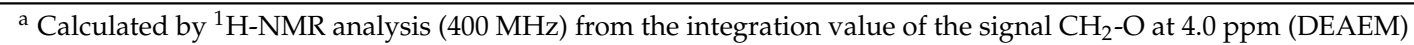
in relation with the signal at $3.65 \mathrm{ppm}$ corresponding to the known number of methylenes $\left(\mathrm{CH}_{2} \mathrm{CH}_{2}-\mathrm{O}\right)$ of the repeating unit in the PEG-CTA (see Figure S1 in Supplementary Material file). b Obtained by dynamic light scattering. " Statistics of sizes in Figure S7 in Supplementary material file. ${ }^{\mathrm{d}}$ Calculated by using the equations: $<\mathrm{h}^{2}>^{0.5}=\mathrm{n}_{\text {PDEAEM }}{ }^{*}(0.254)$ and $\mathrm{D}_{\mathrm{h}}=2^{*}(0.665 / \sqrt{ } 6)^{*}<\mathrm{h}^{2}>^{0.5}$ for the PDEAEM segment extension, $4.46 \mathrm{~nm}$ for the $\mathrm{PEG}_{51}$, and $10.88 \mathrm{~nm}$ for the $\mathrm{PEG}_{122}$. 
To confirm the morphology of the suspected polymersomes, AFM and TEM analysis were performed on the polymer aggregates obtained by the solvent exchange methodology. The obtained micrographs are presented in Figure 4. All the obtained aggregates possess semispherical shapes with measured diameters comparable to that obtained by DLS, observing a greater standard deviation for the $\mathrm{P}_{122} \mathrm{D}_{96}$ aggregates. TEM micrographs show a clearer contrast in the middle of the aggregates with a distinctly darker contrast in the periphery. This is a result of the preferential staining of the DEAEM units in the aggregates which are concentrated in the periphery of the aggregates, supporting the double layer formation with a water core (vesicle type polymersomes).

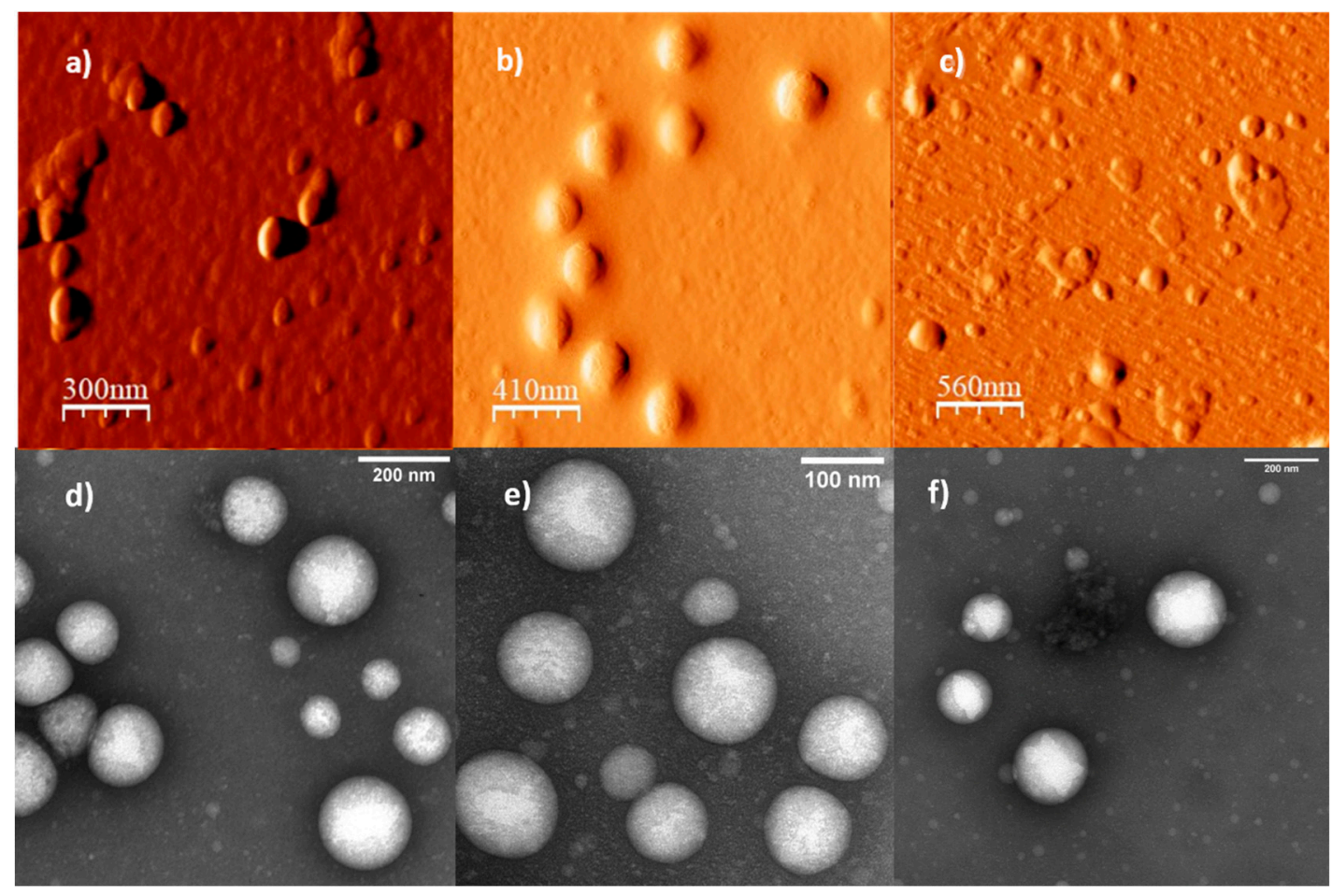

Figure 4. AFM and TEM micrographs for some aggregates obtained by solvent exchange for the copolymers: (a) AFM image of $\mathrm{P}_{51} \mathrm{D}_{47}$, (b) AFM images of $\mathrm{P}_{122} \mathrm{D}_{54}$, (c) AFM images of $\mathrm{P}_{122} \mathrm{D}_{96}$, (d) TEM image of $\mathrm{P}_{51} \mathrm{D}_{47}$, (e) TEM image of $\mathrm{P}_{122} \mathrm{D}_{54}$, and (f) TEM image of $\mathrm{P}_{122} \mathrm{D}_{96}$. AFM Images obtained on mica substrate by tapping mode and TEM images with uranyl acetate stained samples on copper grids.

\section{3. $p H$ and Temperature Sensitive Behavior of the PEG-b-PDEAEM Aggregates}

To study the $\mathrm{pH}$-sensitive behavior of PEG- $b$-PDEAEM, $0.5 \mathrm{mg} / \mathrm{mL}$ dispersions of polymersomes in distilled water were used. The $\mathrm{pH}$ of the solution was adjusted by adding $\mathrm{HCl}$ or $\mathrm{NaOH}$ solutions. Figure 5a shows the $\mathrm{pH}$-sensitive behavior of the polymersomes generated from all the prepared copolymers. An increase of the polymersome diameter at $\mathrm{pH}$ values lower than 7 can be observed due to the electrostatic repulsion between the protonated amine groups on the PDEAEM segments. Increases in the $\mathrm{D}_{\mathrm{H}}$ values from 144 to $185 \%$ are observed at a $\mathrm{pH}$ value of 4 (in the case of the copolymers $\mathrm{P}_{122} \mathrm{D}_{96}, \mathrm{P}_{122} \mathrm{D}_{59}$ and $\mathrm{P}_{122} \mathrm{D}_{54}$ ), indicating the destruction of the original polymersome and the formation of larger aggregates (Figure $\mathrm{S} 8$ in the Supplementary material file). In the biologically significant $\mathrm{pH}$ interval from 5.5 to 8 , all the polymersomes are stable, which makes them great candidates for drug delivery applications. The $\mathrm{pH}$-sensitive behavior of the polymersomes was also reflected in the zeta potential analysis (Figure 5b), observing an increase of the total positive charge as the $\mathrm{pH}$ value decreased and a decrease in the zeta potential value when the tertiary amine groups of the PDEAM segments were deprotonated at higher $\mathrm{pH}$ values [33]. 
a)

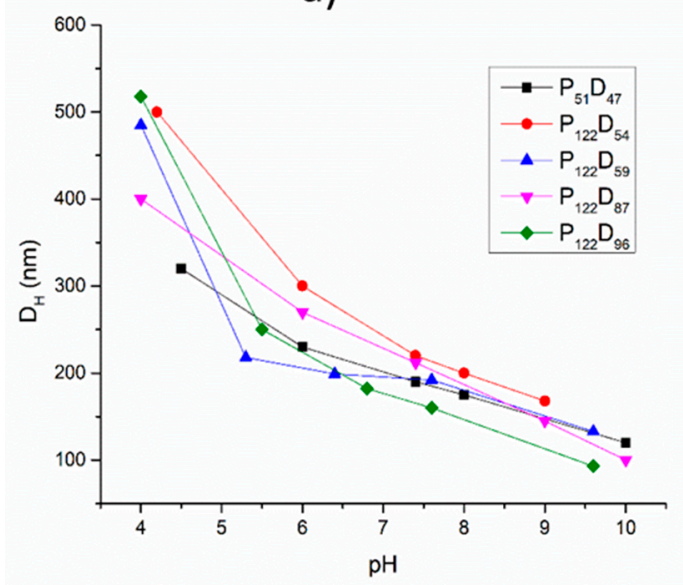

b)

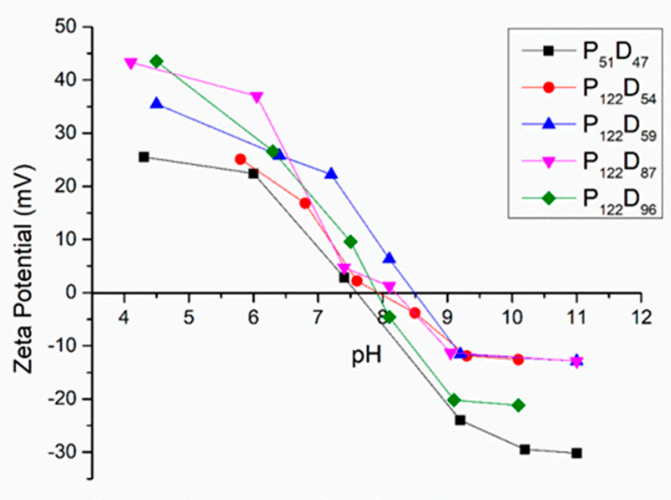

Figure 5. pH-sensitive behavior for aggregates prepared from block copolymers: (a) Hydrodynamic diameters obtained by DLS $(0.5 \mathrm{mg} / \mathrm{mL}$ dispersion) and (b) Zeta potential measurements on polymer aggregates.

At the physiological $\mathrm{pH}$ value of 7.4, the polymersomes presented positive zeta potential values of +0.5 to $+25 \mathrm{mV}$ depending on the PDEAEM content. These value results are appropriate for a possible cell internalization of the aggregates.

The temperature sensitivity of the obtained polymersomes was confirmed by DLS measurements, one of several methods used to determine the LCST [35]. Aqueous dispersions of polymersomes $(0.5 \mathrm{mg} / \mathrm{mL}, \mathrm{pH}$ adjusted at 7.4) were used; these dispersions were studied using a heating ramp of $2{ }^{\circ} \mathrm{C} / 5 \mathrm{~min}$, from 25 to $55^{\circ} \mathrm{C}$. As seen in Figure 6, a slight contraction $\left(5 \%\right.$ in the $\left.\mathrm{D}_{\mathrm{H}}\right)$ of the polymersomes due to the temperature increase was observed. Taking the numerical derivate of the data (blue curve), a phase transition temperature of $37-38{ }^{\circ} \mathrm{C}$ was calculated. The same behavior was observed for all the copolymers. Since it is known that the temperature-sensitive behavior depends on the hydrophobic-hydrophilic balance of the copolymers [36], it is expected that the $\mathrm{pH}$ of the aqueous environment will strongly affect this behavior for the title copolymers. In fact, it has been reported that for PDEAEM nanogels, the LCST is shifted from $38{ }^{\circ} \mathrm{C}$ to $65{ }^{\circ} \mathrm{C}$ when the pH of the aqueous environment changes from $\mathrm{pH} 7.3$ to $\mathrm{pH}$ 6.7, and at $\mathrm{pH}$ values lower than 6.5 there is no LCST [37]. The PEG- $b$-PDEAEM block copolymers employed in this study did not show a transition temperature in the range between 25 and $55^{\circ} \mathrm{C}$ when studied at a $\mathrm{pH}$ of $5.8-\mathrm{a} \mathrm{pH}$ where the ionization of the DEAEM units is strong.

a)

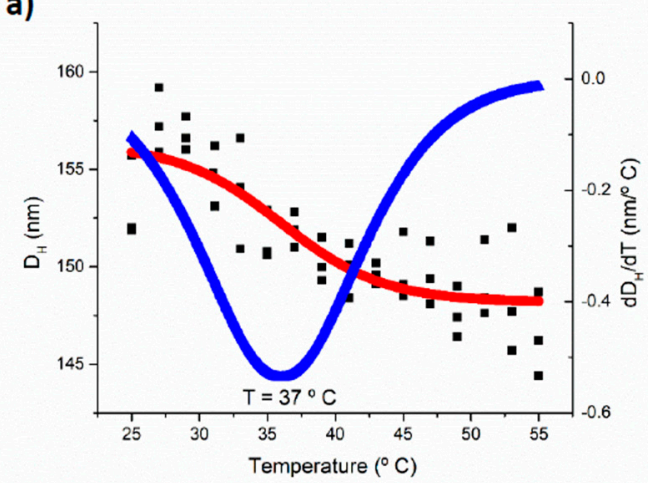

b)

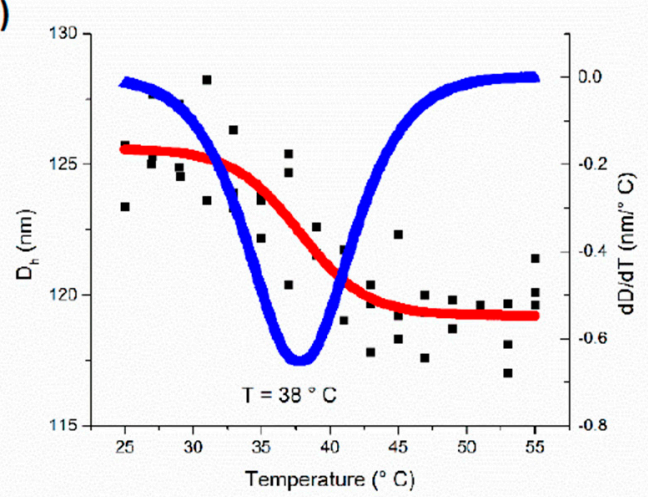

Figure 6. Temperature sensitivity of polymer aggregates at a pH 7.4: (a) aggregates formed by $\mathrm{P}_{122} \mathrm{D}_{54}$ and (b) aggregates formed by $\mathrm{P}_{122} \mathrm{D}_{87}$. 


\subsection{Gold Nanorod Synthesis}

Gold nanorods were synthetized by a seed-mediated growth method. Varying the age of the gold seeds, two different types of gold nanorods with different aspect ratios where synthetized.

Seeds aged for $2 \mathrm{~h}$ lead to gold nanorods with a smaller width and, as a consequence, a higher aspect ratio than the ones obtained with the 8-h-aged seeds. For the gold nanorods prepared using 2-h-aged seeds (AuNR-846), the measured absorbance spectrum, right after the synthesis, is shown in Figure 7a. The spectrum reveals a longitudinal Surface Plasmon Resonance (LSPR) band at $846 \mathrm{~nm}$. By FE-SEM microscopy observation, an average size of $7.33 \pm 1.16 \mathrm{~nm}$ in width and $42.12 \pm$ $6.6 \mathrm{~nm}$ in length was estimated, which results in an aspect ratio of about 5.7. In the case of the gold nanorods synthetized using 8-h-aged seeds (AuNR-761) a LSPR band at $761 \mathrm{~nm}$ is observed (Figure 7c). By FE-SEM microscopy observation, an average diameter of $12.13 \pm 2.3 \mathrm{~nm}$ in width and $49.38 \pm 6 \mathrm{~nm}$ in length was estimated; therefore, the aspect ratio resulted to be 4.07 . These results coincide with the reports from C.J. Murphy et al. [38] which demonstrated that a higher aspect ratio of AuNRs results in a shift of SPR to higher wavelengths.
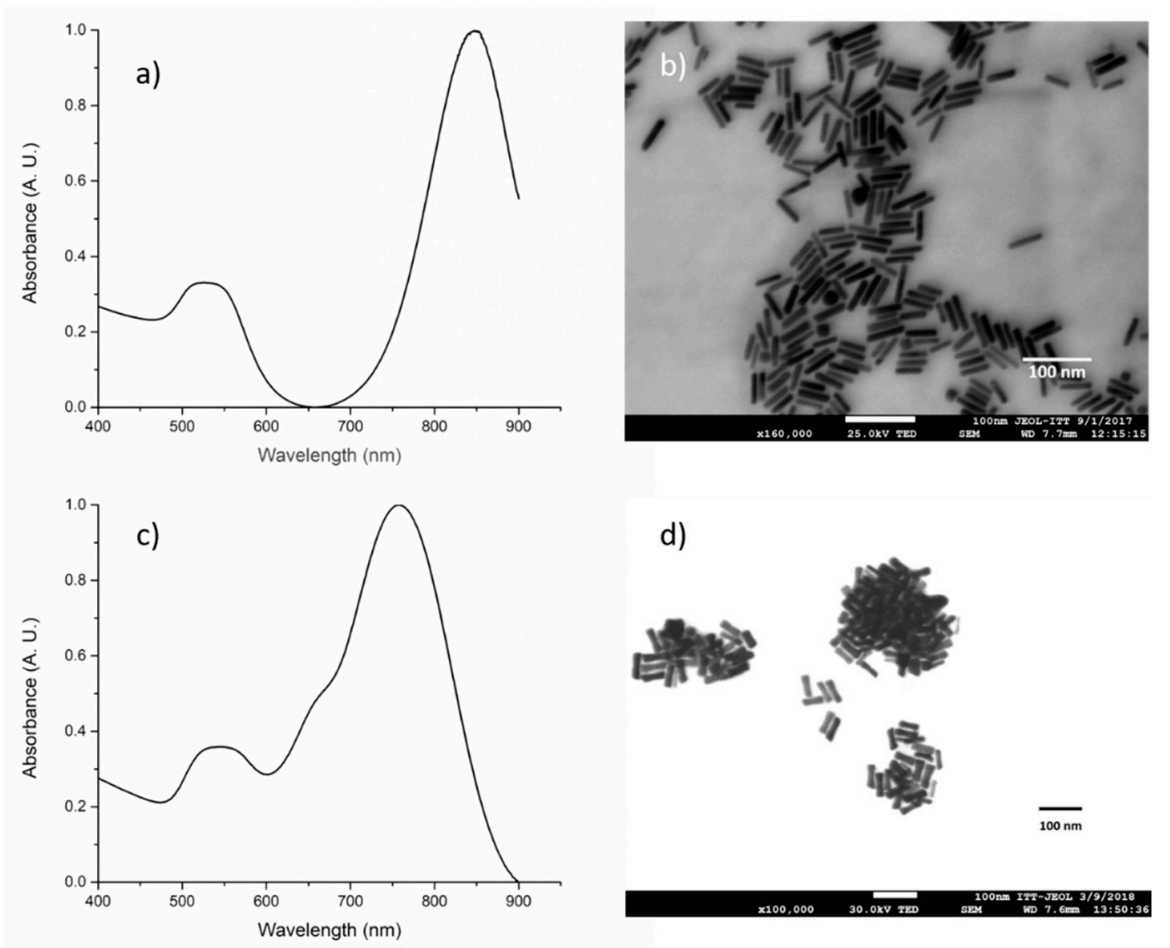

Figure 7. Gold nanorod's characterization: (a) UV-Visible spectrum, (b) FE-SEM micrograph for the gold nanorods synthetized from 2-h-aged gold seeds, (c) UV-Visible spectrum, and (d) FE-SEM micrograph for the gold nanorods synthesized from 8-h-aged gold seeds.

\subsection{Gold Nanorod's Encapsulation}

By modifying the methodology reported by Zhong et al. [25], the synthetized gold nanorods were encapsulated on selected block copolymers, observing in all cases a displacement of the longitudinal LSPR band to higher wavelengths (Figure 8). In the case of gold nanorods with a LSPR longitudinal band of $846 \mathrm{~nm}$, right after the purification it was observed that the LSPR band was displaced to 867 nm (AuNR-846). 


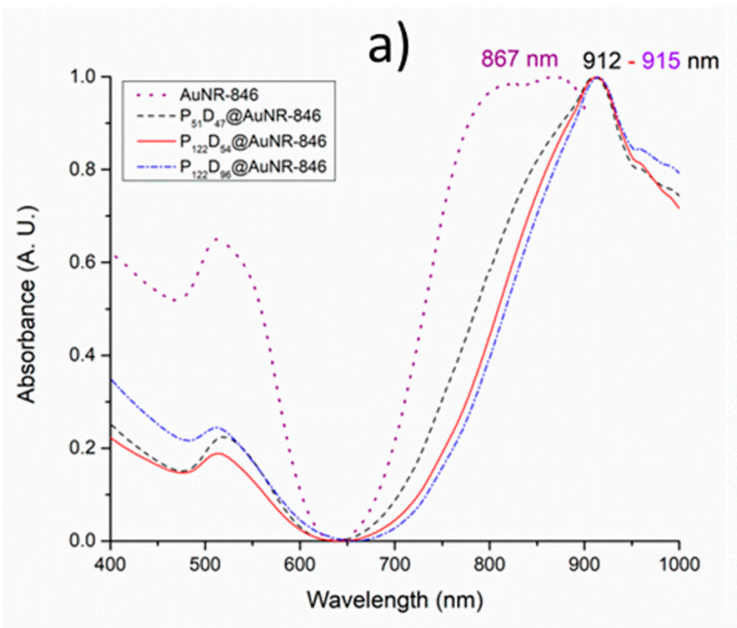

c)

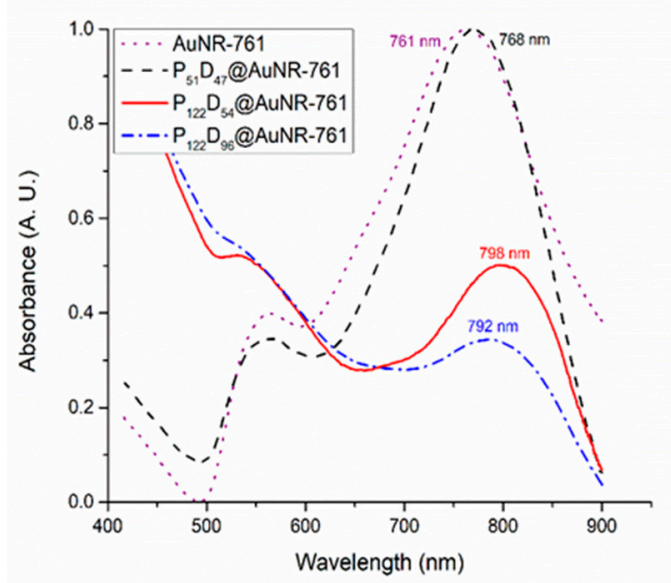

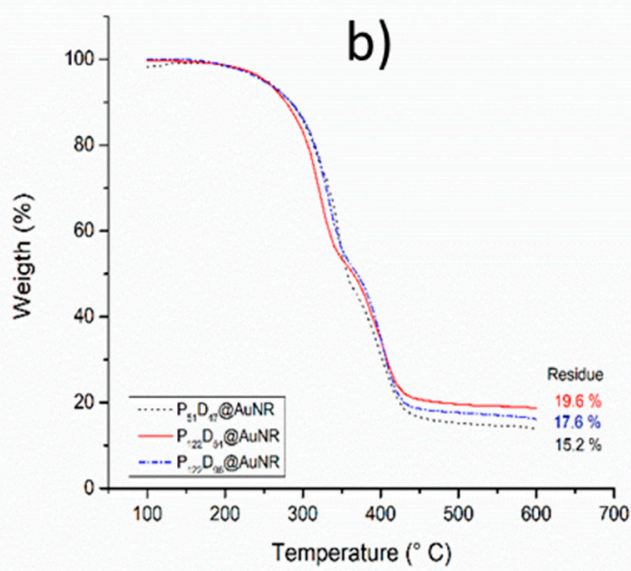

d)

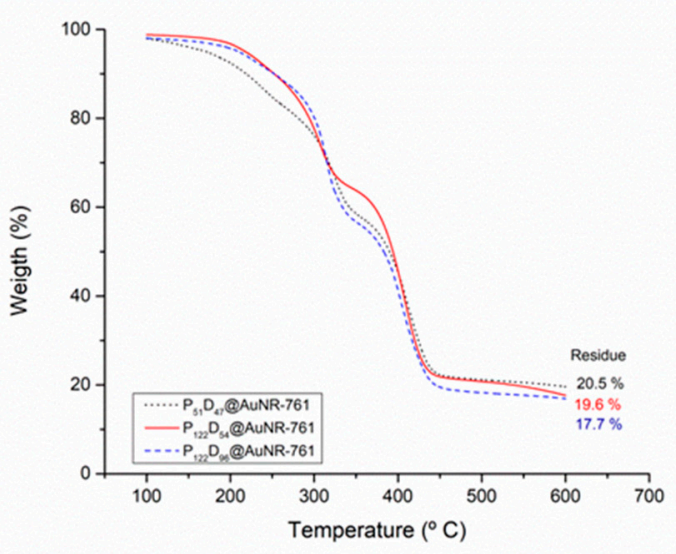

Figure 8. Gold nanorod filled polymersome's characterization: (a) UV-Visible spectrum, and (b) TGA thermograms for the gold nanorods synthetized from $2 \mathrm{~h}$ aged gold seeds; (c) UV-Visible spectrum, and (d) TGA-thermograms for the gold nanorods synthesized from $8 \mathrm{~h}$ aged gold seeds.

This is probably due to agglomeration between the gold nanoparticles after the CTAB removal and a possible increase of the local refractive index. For the encapsulated nanorods, the LSPR longitudinal bands were further displaced to values around 912 and $915 \mathrm{~nm}$ (Figure 8a). By TGA, the block copolymers show two decomposition steps, the first one between 200 and $350{ }^{\circ} \mathrm{C}$ and the second one between 350 and $450{ }^{\circ} \mathrm{C}$ (thermograms of the block copolymers without AuNRs in Figure S9, in the Supplementary material file). After heating to $600^{\circ} \mathrm{C}$, the obtained residues for the copolymers $\mathrm{P}_{51} \mathrm{D}_{47}, \mathrm{P}_{122} \mathrm{D}_{54}$ and $\mathrm{P}_{122} \mathrm{D}_{96}$ are between 4.3 and 5.5\%. By the encapsulation of AuNR-761, also a slight displacement in the LSPR longitudinal band of the gold nanorods was observed as a result of the AuNR agglomeration after the CTAB removal. For the encapsulated nanorods, the LSPR longitudinal band was displaced only minimally to a maximum of $798 \mathrm{~nm}$ (Figure 9c). Unlike the high wavelength values obtained for the LSPR of the copolymer encapsulated AuNR-846 $(\sim 910 \mathrm{~nm})$, the resonances centered around 768-798 $\mathrm{nm}$ are more suitable to obtain a good photothermal efficiency by irradiating with a wavelength of $808 \mathrm{~nm}$. The encapsulated AuNR content in the polymersomes was determined by TGA analysis, subtracting the residue from the block copolymers to those of the $\mathrm{PEG}_{\mathrm{m}}-b-\mathrm{PDEAEM}_{\mathrm{n}} @ A u N R$ materials. In the case of AuNR-761, the content in the polymersomes range from $\sim 12$ to $\sim 16 \%$ by weight (Figure 8d) while the loading efficiency of AuNR ranges from 43 to $45 \%$ (data in Table 3). 

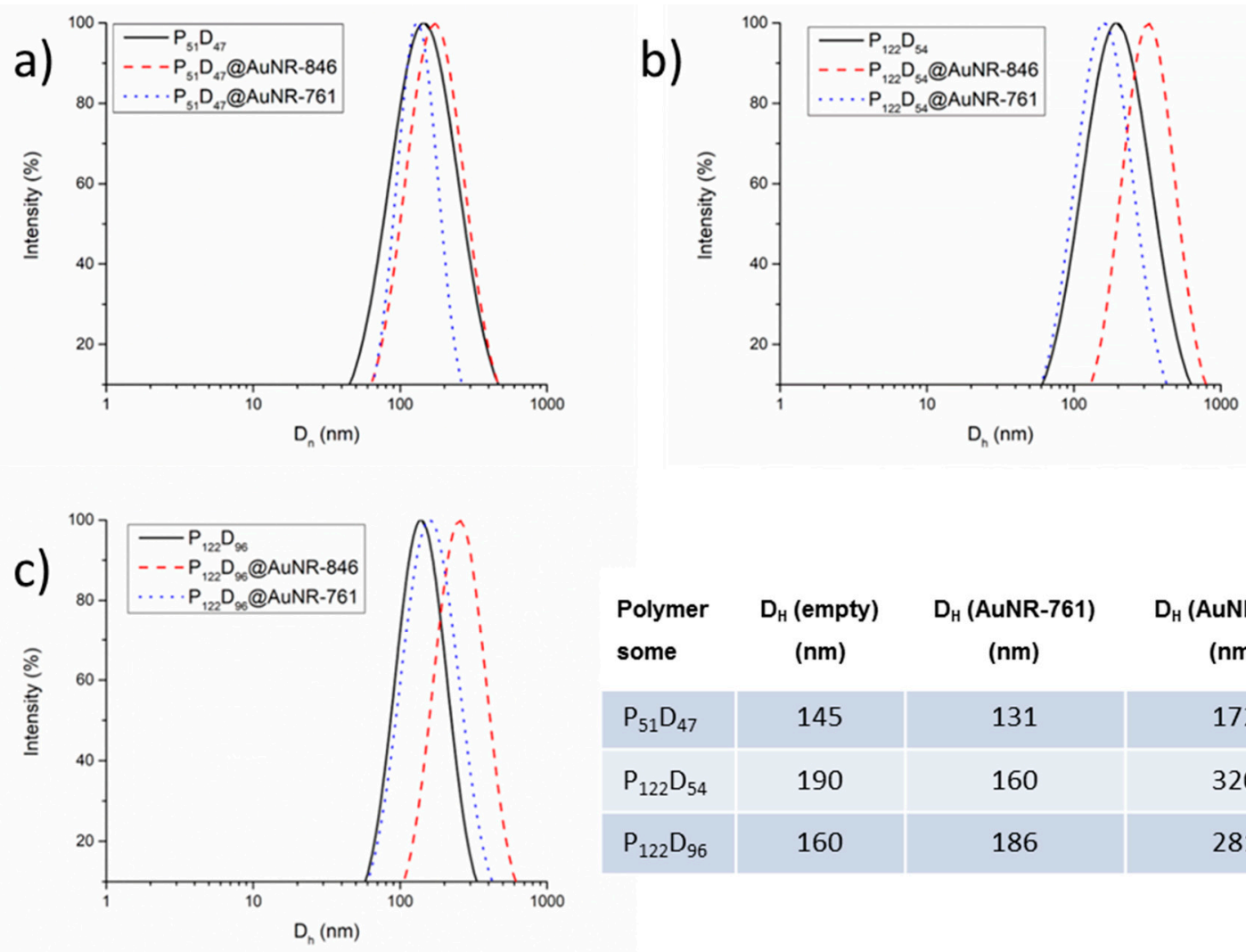

\begin{tabular}{|l|c|c|c|}
\hline $\begin{array}{l}\text { Polymer } \\
\text { some }\end{array}$ & $\begin{array}{c}\mathrm{D}_{\mathrm{H}} \text { (empty) } \\
(\mathbf{n m})\end{array}$ & $\begin{array}{c}\mathrm{D}_{\mathrm{H}} \text { (AuNR-761) } \\
(\mathbf{n m})\end{array}$ & $\begin{array}{c}\mathrm{D}_{\mathrm{H}} \text { (AuNR-846) } \\
(\mathbf{n m})\end{array}$ \\
\hline $\mathrm{P}_{51} \mathrm{D}_{47}$ & 145 & 131 & 172 \\
\hline $\mathrm{P}_{122} \mathrm{D}_{54}$ & 190 & 160 & 320 \\
\hline $\mathrm{P}_{122} \mathrm{D}_{96}$ & 160 & 186 & 281 \\
\hline
\end{tabular}

Figure 9. Comparison between the $\mathrm{D}_{\mathrm{H}}$ of empty polymersomes and AuNR-846/AuNR-761 loaded polymersomes in PBS at $\mathrm{pH}$ 7.4: (a) from $\mathrm{P}_{51} \mathrm{D}_{47}$, (b) $\mathrm{P}_{122} \mathrm{D}_{54}$, (c) and $\mathrm{P}_{122} \mathrm{D}_{96}$.

Table 3. DOX loading efficiency (DLE $\mathrm{DOX}_{\text {) }}$ ) and DOX loading content (DLC $\mathrm{DOX}_{\mathrm{DO}}$ ) and equivalent values for AuNR loadings calculated for the obtained polymersomes.

\begin{tabular}{lcccc}
\hline \multicolumn{1}{c}{ Polymersome } & DLE $_{\text {DOX }}(\mathbf{\%})$ & LE $_{\text {AuNR }}{ }^{\mathbf{a}} \mathbf{( \% )}$ & DLC $_{\text {DOX }} \mathbf{( \% )}$ & LC $_{\text {AuNR }} \mathbf{b}$ \\
\hline $\mathrm{P}_{51} \mathrm{D}_{47}$ & 52.0 & - & 12.0 & - \\
$\mathrm{P}_{51} \mathrm{D}_{47} @ A u N R-761$ & 47.4 & 44.7 & 10.9 & 16.1 \\
$\mathrm{P}_{122} \mathrm{D}_{54}$ & 46.7 & - & 10.8 & - \\
$\mathrm{P}_{122} \mathrm{D}_{54} @ A u N R-761$ & 44.3 & 42.5 & 10.2 & 15.3 \\
$\mathrm{P}_{122} \mathrm{D}_{96}$ & 48.3 & - & 11.1 & - \\
$\mathrm{P}_{122} \mathrm{D}_{96} @ A u N R-761$ & 44.7 & 33.8 & 10.3 & 12.2 \\
\hline
\end{tabular}

${ }^{a}$ Loading efficiency of AuNR ( LE $_{\text {AuNR }}$ ) as determined by Equation (1) but using data from AuNR. ${ }^{b}$ Loading content of AuNR ( $\left(\mathrm{LC}_{\mathrm{AuNR}}\right)$ as determined by TGA analysis, subtracting the residue from the block copolymers to those of the $\mathrm{PEG}_{\mathrm{m}}-b$-PDEAEM $\mathrm{n} @ \mathrm{AuNR}$ materials.

The encapsulation of AuNRs in the polymersomes has a side effect-a change in the overall diameter of the polymersomes. Figure 9 shows the distribution of sizes by DLS for the empty polymersomes as compared to the AuNR-761 and AuNR-846 filled polymersomes. For the block copolymer containing a short PEG segment $\left(\mathrm{P}_{51}\right)$, the size changes are small $(\sim 19 \%)$; however, for the block copolymers with a larger PEG segment $\left(\mathrm{P}_{122}\right)$, the size increase goes up to $\sim 75 \%$, suggesting that the introduction of AuNRs alters the aggregation equilibrium of block copolymers resulting in larger polymersome formation in this case.

Interestingly, this effect is larger for the AuNR-845 loaded polymersomes, probably because these AuNRs are also larger in size making it more difficult to be encapsulated inside the polymersomes.

\subsection{Photothermal Heating under NIR laser Irradiation}

By irradiating the AuNRs with NIR laser light (wavelength of $808 \mathrm{~nm}$ ), a heating of the surroundings of the AuNRs is expected to appear. Depending on the amount of generated heat by the irradiated 
AuNRs, the temperature reached could lead to one of the following results: at temperatures higher than $43{ }^{\circ} \mathrm{C}$, protein denaturalization by hyperthermia may occur $[39,40]$; while a smaller temperature increment could lead to a thermosensitive response of the PDEAEM blocks of the PEG- $b$-PDEAEM polymersomes, resulting in squeezing out the encapsulated water from the polymersome; this effect could be used to enhance drug delivery [41]. An interesting aspect of combining a nanocarrier AuNRs with a chemotherapeutic agent, like doxorubicin (DOX), is an expected synergic therapeutic effect: The hyperthermia generated by the NIR-Irradiation can sensitize the cancer cells, promoting the drug delivery directly into the tumors, increasing the therapeutic effects of the separate photothermal and chemotherapy [42,43].

As seen in Figure 10, with a laser output power of $450 \mathrm{~mW}$, water did not show an increment in temperature during the $15 \mathrm{~min}$ of irradiation, because the water molecules do not absorb light at $808 \mathrm{~nm}$. However, irradiation of the polymersome-encapsulated AuNRs, increments the temperature of the medium between 17 and $24{ }^{\circ} \mathrm{C}$ above room temperature (Figure 10a). Differences in AuNRs concentrations are expected to be rather small among samples, as estimated from the thermogravimetric analysis data (Figure $8 \mathrm{~d}$ ).
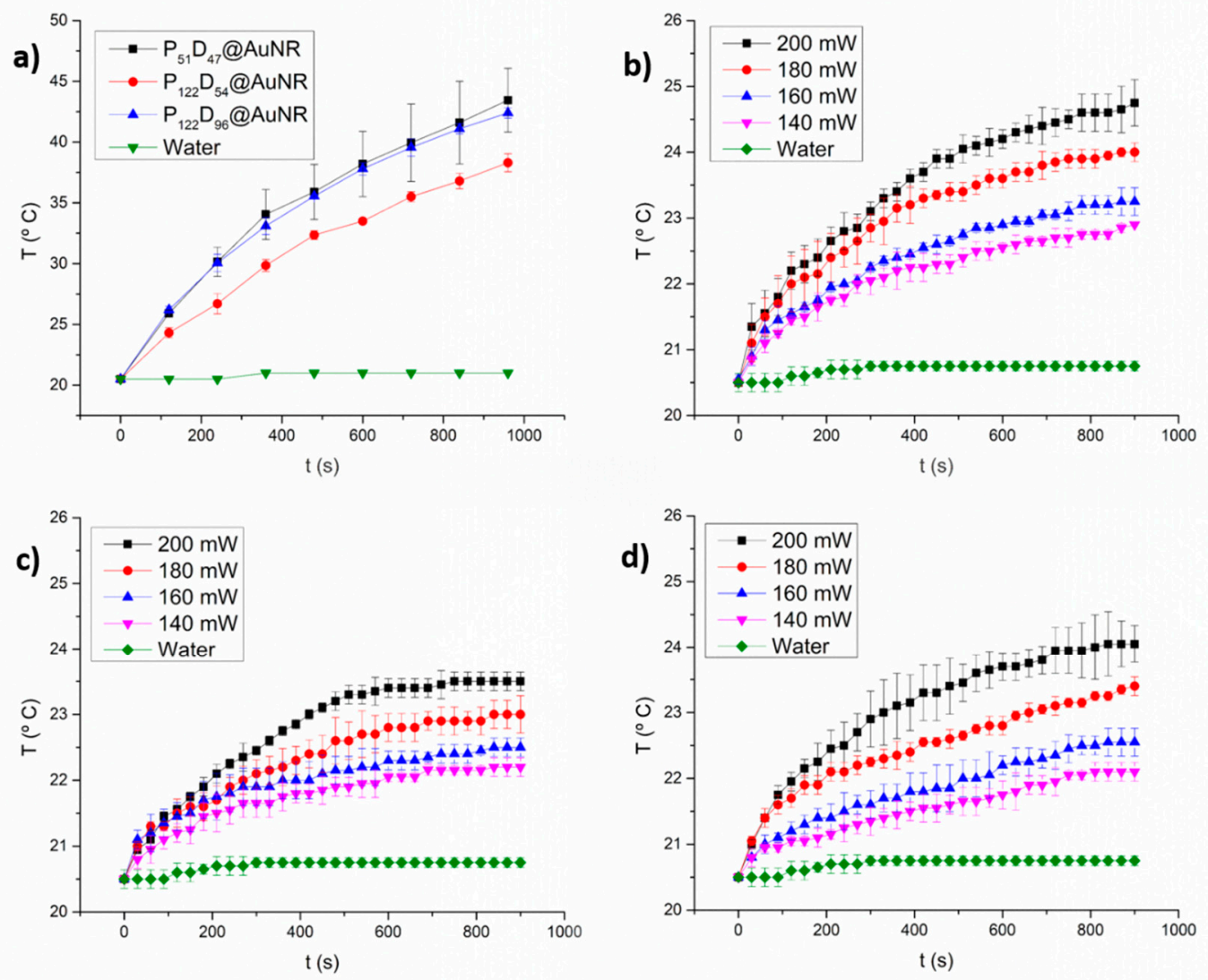

Figure 10. Time-dependent temperature increase due to NIR laser irradiation ( $808 \mathrm{~nm}$ ) of $\mathrm{PEG}_{\mathrm{n}}-b$ PDEAEM $_{\mathrm{m}} @$ AuNR dispersions in distilled water $(0.5 \mathrm{~m} / \mathrm{mL}):(\mathbf{a})$ at $450 \mathrm{~mW}$, (b) PEG $_{51}-b-$ PDEAEM $_{47} @$ AuNR varying the laser output power, (c) PEG $_{122}-b-$ PDEAEM $_{54} @ A u N R$ varying the laser output power and (d) $\mathrm{PEG}_{122}-b$-PDEAEM 96 @AuNR varying the laser output power.

At lower laser output powers, temperature increments between $5{ }^{\circ} \mathrm{C}(200 \mathrm{~mW})$ and $1.5^{\circ} \mathrm{C}(140 \mathrm{~mW})$ are reached after $15 \mathrm{~min}$ of irradiation (Figure $10 \mathrm{~b}-\mathrm{d}$ ). Although the measurements represent only macroscopic spatial averages and are not necessarily representative of the local temperature at the micro scale, it is possible that the temperature increments with laser output powers lower than $200 \mathrm{~mW}$ may be too small to obtain a significant response for NIR-triggered drug release experiments. 


\subsection{Load and Controlled Release of DOX from PEG-b-PDEAEM Polymersomes}

\subsubsection{DOX Loading}

The DOX-loaded PEG- $b$-PDEAEM polymersomes (with and without AuNR) were obtained by nanoprecipitation or solvent exchange, an effective bottom up strategy which allows the encapsulation of both hydrophobic and hydrophilic drugs [44]. To a DMSO solution of DOX and the PEG- $b$-PDEAEM block copolymers, PBS with a $\mathrm{pH}$ value of 7.4 was added to allow the formation of the drug-loaded polymersomes. Given the $\mathrm{pH}$-sensitive properties of the empty PEG- $b$-PDEAEM polymersomes, and knowing from the literature that DOX possess a $\mathrm{pK}_{\mathrm{a}}$ value of 8.4 for the daunosamine- $\mathrm{NH}_{3}$ group [45], it is expected that at $\mathrm{pH} 7.4$, the amine moieties present in both components are only slightly protonated, allowing the encapsulation of DOX in the polymersome. As seen in Table 3, DOX-loading efficiencies between 47 and $52 \%$ and DOX loading contents between 10.8 and $12 \%$ for the polymersomes without AuNR were obtained; these parameters are better (almost two times higher) than those reported for similar polymersomes in the literature [46]. These percentages decrease slightly when AuNR are loaded in the polymersomes.

Drug release experiments were conducted at two different $\mathrm{pH}$ values (for the DOX and the AuNR-DOX containing polymersomes). Additional irradiation of the AuNR containing polymersomes was performed every hour for $5 \mathrm{~min}$ with a wavelength of $808 \mathrm{~nm}$. Free DOX, dissolved in PBS at pH 7.4 and treated under the same conditions as the test materials, was used as a control for each experiment.

\subsection{2. $\mathrm{pH}$ Triggered DOX Release}

A pH-controlled DOX release has been a goal in different investigations using nanocomposites over the last years [43,46-49]; since it is known that the tumor $\mathrm{pH}$ and endosomal $\mathrm{pH}$ is slightly acidic, the $\mathrm{pH}$ change can be used as an on-demand drug release trigger. The studies of the $\mathrm{pH}$ sensitivity of the obtained polymersomes showed that at $\mathrm{pH}$ values lower than 7 , an increment in the $\mathrm{D}_{\mathrm{H}}$ occurs due the electrostatic repulsion between the protonated amine groups on the PDEAEM segments. This should not change much if the AuNRs are encapsulated (see Figure S10 in the Supplementary Material File). For the $\mathrm{P}_{51} \mathrm{D}_{47}$ polymersomes (Figure $11 \mathrm{a}$ ), during the first $6 \mathrm{~h}, 20 \%$ of the loaded DOX is released at $\mathrm{pH}$ 7.4. From this time on, there is only a slight increase in the release rate (22\%) up to $24 \mathrm{~h}$; however, when AuNRs are included, there is a small increase in the rate of release already after $10 \mathrm{~h}$. At $\mathrm{pH} 5.8$, the effect of the $\mathrm{pH}$-sensitive behavior of the polymersomes on the rate of release is observed already after $2 \mathrm{~h}$, reaching a 33\% release rate in $24 \mathrm{~h}$. Another interesting observation is that, although the polymersomes that do not contain AuNR accept a higher load of DOX, the polymersomes with AuNR at $\mathrm{pH} 5.8$ show a higher DOX release rate, reaching $40.3 \%$ at $24 \mathrm{~h}$. For the $\mathrm{P}_{122} \mathrm{D}_{54}$ polymersomes (Figure 11b), a similar behavior is observed; however, for the $\mathrm{P}_{122} \mathrm{D}_{96}$ polymersomes (Figure 11c), the $\mathrm{pH}$-sensitive behavior is more evident, while at a $\mathrm{pH}$ of 7.4 , only $20 \%$ of the loaded DOX is released; at a $\mathrm{pH}$ of $5.8,39 \%$ of the loaded DOX is released when no AuNR are incorporated. In the case in which AuNR are also loaded, the released DOX at $24 \mathrm{~h}$ reached a value of $45 \%$. Since at a $\mathrm{pH}$ value of 5.8 a plateau was not reached during the first $24 \mathrm{~h}$ of the release experiment, the experiment was continued for 3 more days taking a sample every $24 \mathrm{~h}$. The released DOX reached $49.6 \%$ in $48 \mathrm{~h}$, $52.2 \%$ in $72 \mathrm{~h}$ and $54.4 \%$ in $96 \mathrm{~h}$. The effect of the AuNR accelerating the release rate of DOX in both types of polymersomes may result from steric destabilization of the polymersome double layer given the large size and elongated form of the AuNRs. In Figure 11c, a schematic representation is shown of an expanded polymersome as a result of the electrostatic repulsion between the protonated amine groups on the PDEAEM blocks, creating channels for the release of the encapsulated DOX in the media, channels that are not present at $\mathrm{pH}=7.4$ where the protonation of PDEAEM is only minimal. 

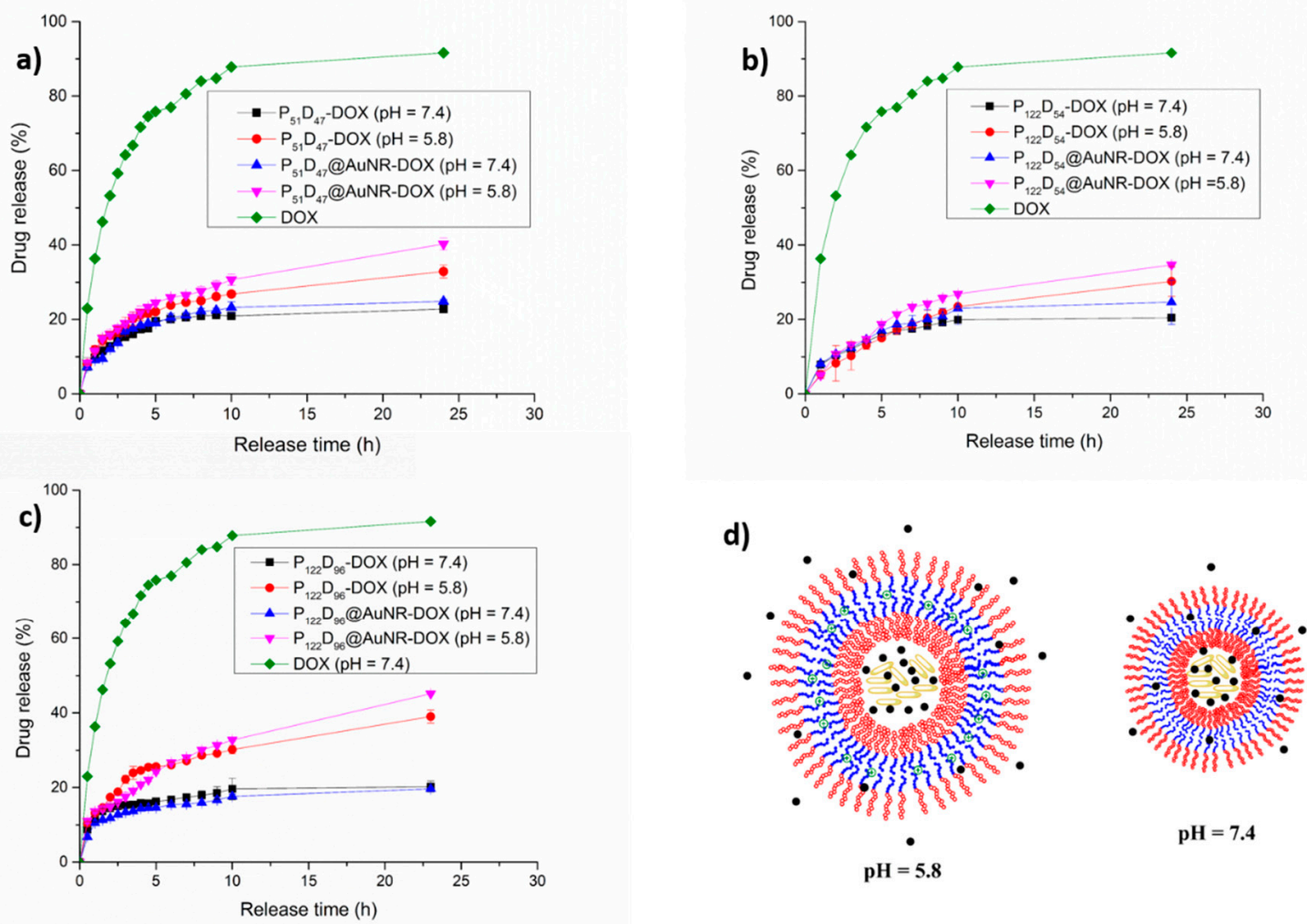

Figure 11. In vitro release profiles for DOX and AuNR-DOX loaded polymersomes at different $\mathrm{pH}$ values: (a) $\mathrm{P}_{51} \mathrm{D}_{47}$ polymersomes, (b) $\mathrm{P}_{122} \mathrm{D}_{54}$ polymersomes, (c) $\mathrm{P}_{122} \mathrm{D}_{96}$ polymersomes and (d) schematic representation of polymersomes at $\mathrm{pH}$ values of 5.8 and 7.4.

\subsubsection{NIR-irradiation Triggered DOX Release}

From the NIR irradiation temperature increment studies, it was confirmed that the temperature reached after $5 \mathrm{~min}$ of irradiation with a laser output power of $450 \mathrm{~mW}$, is high enough to allow for a thermosensitive response of the PEG- $b$-PDEAEM blocks in the polymersomes. The temperature-driven contraction of the polymersome may result in squeezing out the encapsulated DOX, nevertheless it is important to note that the change on the $\mathrm{D}_{\mathrm{H}}$ of the polymersome due to a temperature change is lower than the observed $\mathrm{pH}$-change. As seen in Figure 12a, for the $\mathrm{P}_{51} \mathrm{D}_{47}$ polymersomes there is a slight increment on the released DOX at pH 7.4 due the NIR-irradiation during the first $10 \mathrm{~h}$ of the experiment. After $24 \mathrm{~h}$ of the experiment, the difference between the irradiated and the non-irradiated samples is about $10 \%$, reaching a DOX release of $32 \%$, which is comparable with the DOX release at a $\mathrm{pH}$ value of 5.8 without NIR irradiation (Figure 11a). For the $\mathrm{P}_{122} \mathrm{D}_{54}$ polymersomes (Figure $12 \mathrm{~b}$ ), during the first $8 \mathrm{~h}$ of the drug release experiment, the difference between the NIR-irradiated and non-irradiated polymersomes is very small. At the 9 th hour, the release is boosted from 24 to $29 \%$, reaching a $42 \%$ DOX release at $24 \mathrm{~h}$, as contrasted with the $25 \%$ reached by the non-irradiated system. In the case of the $\mathrm{P}_{122} \mathrm{D}_{96}$ polymersomes (Figure 12c), an important difference between the release profiles of the NIR-irradiated and non-irradiated systems is observed. For the irradiated system, the DOX release is boosted from 13 to $19 \%$ at the 4 th hour, while for the non-irradiated system, the DOX release only increases from 11 to $13 \%$. During the first $10 \mathrm{~h}$ of the experiment, the DOX release for the non-irradiated system increases pretty slowly, reaching an 18\% DOX release; while for the irradiated system, at the same time a $27 \%$ of DOX release is reached. Unlike the $P_{51} D_{47}$ polymersome, for the $\mathrm{P}_{122} \mathrm{D}_{96}$ polymersome, there is an important difference between the amounts of released DOX due the NIR-irradiation at $24 \mathrm{~h}$, being 38 and $45 \%$ respectively. In Figure 12d, a schematic representation is shown of the non-irradiated polymersome and the collapsed (irradiated) polymersome as a result 
of a thermosensitive response due to the temperature increment of the media produced by the NIR irradiated AuNRs, releasing more DOX.

a)

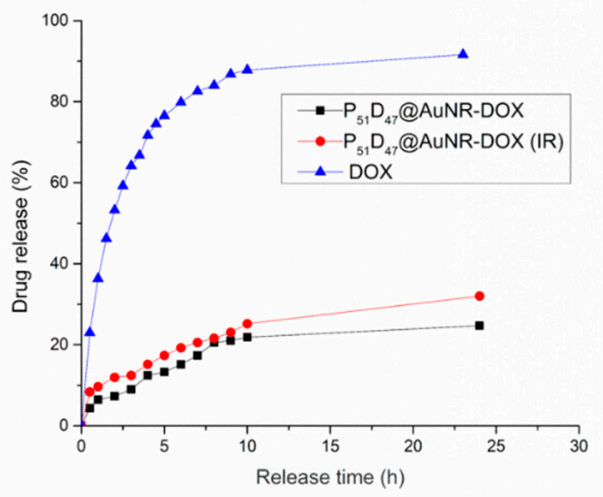

c)

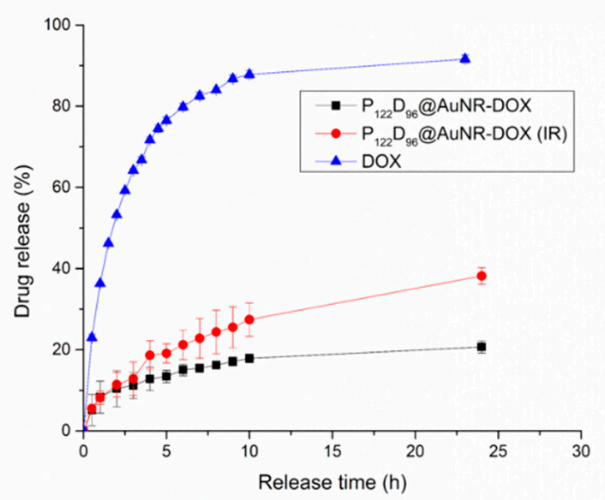

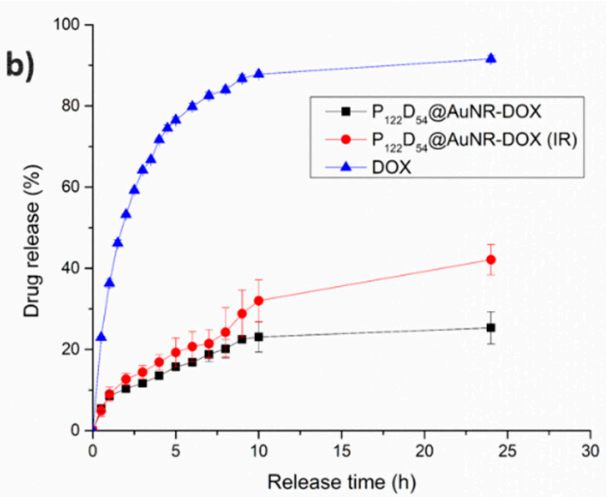

d)

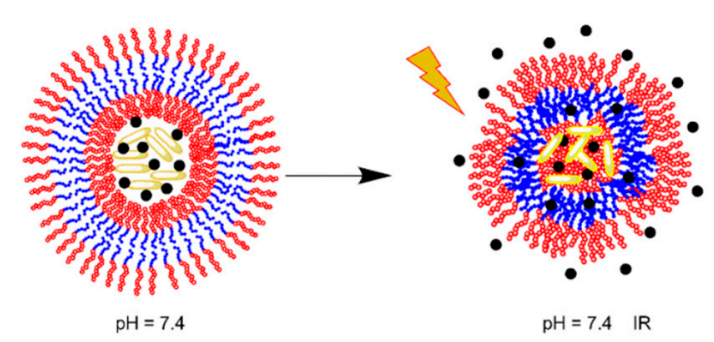

Figure 12. In vitro release profiles for DOX and AuNR-DOX-loaded polymersomes at $\mathrm{pH}$ 7.4. Effect of NIR irradiation: (a) $\mathrm{P}_{51} \mathrm{D}_{47}$ polymersomes, (b) $\mathrm{P}_{122} \mathrm{D}_{54}$ polymersomes, and (c) $\mathrm{P}_{122} \mathrm{D}_{96}$ polymersomes.

(d) Model of polymersomes behavior.

\subsubsection{Combined $\mathrm{pH}$ and NIR-irradiation Triggered Release}

While the increment in the released fraction of DOX by effect of the change to a lower $\mathrm{pH}$ value in the medium is due to the increment in size and permeability of the polymersome, the observed increment of released DOX due to the NIR irradiation of AuNR-containing polymersomes is a result of a contraction because the phase transition temperature of the blockcopolymers is surpassed. So what would be the effect on DOX release of a combination of $\mathrm{pH}$-change with NIR-irradiation? In Figure 13, it is observed that the combination of both effects has a different response for each tested polymersome. In the case of the $\mathrm{P}_{51} \mathrm{D}_{47}$ polymersomes (smaller, with a balance of hydrophilic PEG and $\mathrm{pH}$-ionizable PDEAEM units), the NIR-irradiated system exhibits a higher rate of release from the 5th hour; this could be attributed to the fact that the protonation of the amine groups at the $\mathrm{pH}=5.8$ plus the NIR-irradiation could lead to destabilization of the poymersome, allowing a higher DOX release. However, for the $\mathrm{P}_{122} \mathrm{D}_{54}$ and $\mathrm{P}_{122} \mathrm{D}_{96}$ polymersomes (larger, with higher hydrophilic PEG content than $\mathrm{pH}$-ionizable PDEAEM units), the amount of released DOX is equal or even lower for the irradiated systems as compared to the non-irradiated ones. These observations could be attributed to the following. First, the partially protonated polymersomes have a larger PEG segment and are more stable at $\mathrm{pH} 5.8$. On the other hand, at $\mathrm{pH}$ values lower than 7.4, the transition temperature of PDEAEM polymers tends to increase to higher values [34]. This means that the temperature-driven contraction of the polymersomes cannot be reached with the irradiation levels employed. 

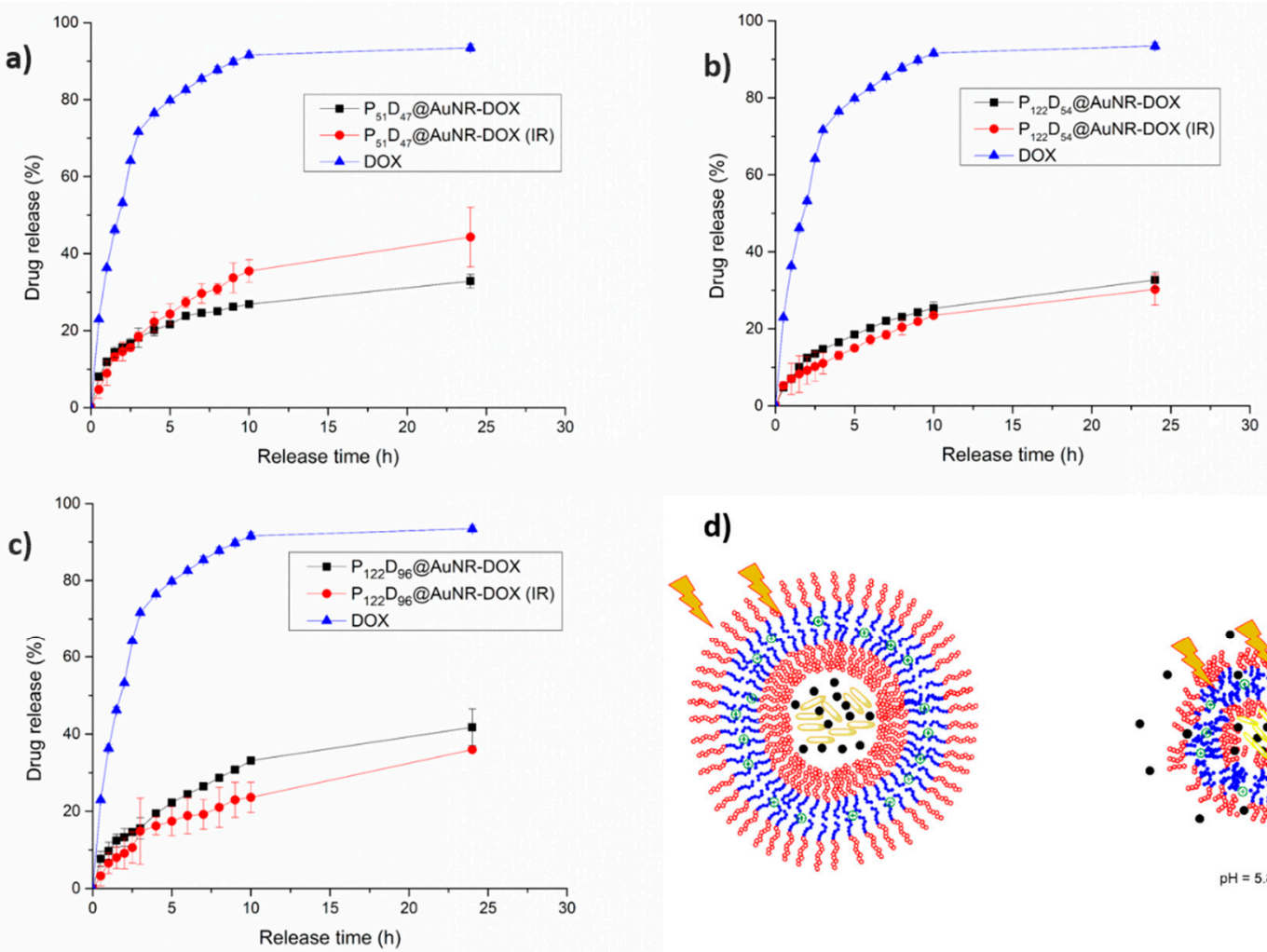

d)
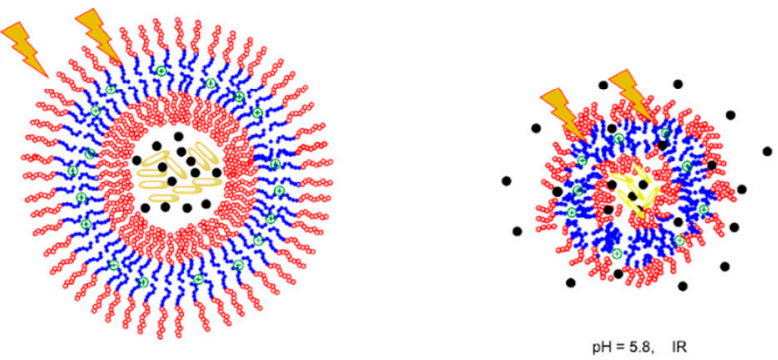

Figure 13. In vitro release profiles for DOX and AuNR-DOX-loaded polymersomes. Effect of NIR irradiation at a $\mathrm{pH}$ value of 5.8: (a) $\mathrm{P}_{51} \mathrm{D}_{47}$ polymersomes, (b) $\mathrm{P}_{122} \mathrm{D}_{54}$ polymersomes, (c) $\mathrm{P}_{122} \mathrm{D}_{96}$ polymersomes. (d) Model of polymersomes behavior.

\section{Conclusions}

Five PEG- $b$-PDEAEM block copolymers were prepared using PEG-macro chain transfer agents containing 51 and 122 units of PEG, changing the PDEAEM block size by RAFT polymerization. The PDEAEM content in the block copolymers was changed from $31 \%$ to $44 \%$ for the copolymers containing the $\mathrm{PEG}_{122}$-macroCTA and was $48 \%$ for the $\mathrm{PEG}_{51}$ copolymer; this resulted in different sizes $\left(D_{H}\right.$ from 100 to $250 \mathrm{~nm}$ ) for the obtained aggregates. The polymer aggregates were prepared by two different techniques, observing that the ones obtained by solvent exchange had lower diameters and narrower distributions of sizes. By AFM, the spherical morphology of the aggregates was confirmed and calculations suggested that polymersomes were obtained. These polymer aggregates were used to encapsulate gold nanorods of different sizes, observing that by the polymer coating the longitudinal surface plasmon resonance band was shifted to higher wavelengths (from 30 to $50 \mathrm{~nm}$ approximately). From the prepared polymer@AuNRs, the best candidates for photothermal applications were the $\mathrm{PEG}_{\mathrm{m}}-b$-PDEAEM $\mathrm{n} @$ AuNR-761 systems, because their LSPR band was close to $800 \mathrm{~nm}$ and they can be efficiently excited by a NIR laser.

The obtained $\mathrm{PEG}_{\mathrm{m}}-b$-PDEAEM $\mathrm{n} @$ AuNR-761 from three different block copolymers $\left(\mathrm{P}_{51} \mathrm{D}_{47}\right.$, $\mathrm{P}_{122} \mathrm{D}_{54}$ and $\mathrm{P}_{122} \mathrm{D}_{96}$ ) contained 12 to $15 \mathrm{wt} \%$ of AuNRs and was further successfully loaded with 10-12 wt $\%$ of the anti-cancer drug doxorubicin to obtain nanometric drug delivery systems with triggered drug release under $\mathrm{pH}$ changes and NIR laser activation. The mechanisms of the enhanced release due to the tested stimuli are completely different: By decreasing the $\mathrm{pH}$ of the media, the polymersome suffers an increment on the $\mathrm{D}_{\mathrm{H}}$, increasing its membrane permeability, while by NIR-irradiation the heat generated by the encapsulated AuNRs leads to a $D_{H}$ decrease on the polymersomes, squeezing out the trapped DOX. By combining both stimuli, for the $P_{51} D_{47}$ polymersome, an increase on the released DOX fraction is observed, which is attributed to the fact that by having a smaller PEG segment, the polymersome double layer is not very stable against possible 
expansion/contraction events, allowing a faster release of the entrapped DOX. In the case of $\mathrm{P}_{122} \mathrm{D}_{54}$ and $\mathrm{P}_{122} \mathrm{D}_{96}$ polymersomes, with a longer PEG segment and lower PDEAEM contents, the overall stability of the polymersomes is higher, even at a high degree of protonation of PDEAEM units (at $\mathrm{pH}$ $=5.8$. . These larger, more stable polymersomes are good candidates for $\mathrm{pH}$-triggered drug delivery or NIR-irradiation triggered drug delivery at $\mathrm{pH}$ 7.4; however, a synergy by combining both effects was not observed. In future studies, the developed $\mathrm{PEG}_{\mathrm{m}}-b$-PDEAEM $\mathrm{n} @ A$ AuNR-761 nanomaterials will be characterized more thoroughly, and their efficacy for the treatment of some cancer cell lines will be tested.

Supplementary Materials: The following are available online at http://www.mdpi.com/2073-4360/11/6/939/s1, Figure S1: ${ }^{1} \mathrm{H}-\mathrm{NMR}$ spectra for Sigma Aldrich ${ }^{\circledR}$ methoxy-Poly(ethylene glycol) of (a) 2000 Da and (b) 5000 $\mathrm{Da}$, Text describing of the Synthesis of the $\mathrm{PEG}_{122}$-macroCTA in detail, Figure S2: ${ }^{1} \mathrm{H}-\mathrm{NMR}\left(400 \mathrm{MHz}, \mathrm{CDCl}_{3}\right)$ spectra for (a) CTA: 4-cyano-4 (dodecylsulfanylthiocarbonyl) sulfanyl pentanoic acid, (b) PEG51-macroCTA, and (c) $P_{122}$-macroCTA, Figure S3: (a) UV-Vis spectra of DOX in DMSO at different concentrations (0-100 $\mu \mathrm{g} / \mathrm{mL}$ ) and (b) Calibration curve of DOX in DMSO at $484 \mathrm{~nm}$, Figure S4: (a) UV-Vis spectra of DOX in PBS at different concentrations $(0-30 \mu \mathrm{g} / \mathrm{mL}$ ) and (b) Calibration curve of DOX in DMSO at $484 \mathrm{~nm}$, Figure S5: GPC traces (RALS-detector) of the copolymers $\mathrm{P}_{51} \mathrm{D}_{47}\left(\mathrm{PEG}_{51}-b\right.$-PDEAEM 47$), \mathrm{P}_{122} \mathrm{D}_{54}\left(\mathrm{PEG}_{122}-b\right.$-PDEAEM 54$), \mathrm{P}_{122} \mathrm{D}_{59}$

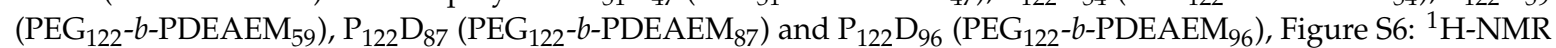
spectra (400 MHz, CDCl 3 ) of synthetized block copolymers: (a) $\mathrm{P}_{51} \mathrm{D} 47$, (b) $\mathrm{P}_{122} \mathrm{D}_{54}$, (c) $\mathrm{P}_{122} \mathrm{D}_{59}$, (d) $\mathrm{P}_{122} \mathrm{D}_{87}$, Figure S7: Statistics of TEM measurements of polymer aggregates: (a) $\mathrm{P}_{51} \mathrm{D} 47$, , (b) $\mathrm{P}_{122} \mathrm{D}_{54}$, (c) $\mathrm{P}_{122} \mathrm{D}_{96}$, Figure $\mathrm{S} 8$ : DLS distribution of sizes for the $\mathrm{P}_{122} \mathrm{D}_{96}$ polymer aggregates obtained by nanoprecipitation in water at different $\mathrm{pH}$ values, Figure S9: TGA-thermograms of synthetized block copolymers: (a) $P_{51} D_{47}$, (b) $P_{122} D_{54}$, (c) $P_{122} D_{96}$, Figure S10: $\mathrm{pH}$ sensitive behavior for polymersomes encapsulating gold nanorod AuNR-761: (a) encapsulated with $\mathrm{P}_{51} \mathrm{D}_{47}$; (b) encapsulated with $\mathrm{P}_{122} \mathrm{D}_{54}$; (c) encapsulated with from $\mathrm{P}_{122} \mathrm{D}_{96}$.

Author Contributions: Conceptualization, N.A.C.-L. and A.L.-C.; Investigation, M.D.-R.; Methodology, J.L.-R.; Resources, A.L.-C. and E.R.M.; Supervision, A.L.-C.; Writing—original draft, M.D.-R.; Writing—review \& editing, N.A.C.-L., A.L.-C., J.L.-R. and E.R.M.

Funding: This research was funded by the National Council of Science and Technology of Mexico (CONACYT). Grants: CB2012-178709, INFR2014-224284 and CB2016-285419.

Acknowledgments: We thank I.A. Rivero (FE-SEM images), V. Miranda (NMR measurements, ITT NMR facilities funded by CONACYT Grant: INFR-2011-3-173395) and A. Ramirez (AFM images) from IT-Tijuana for their technical support. Spectra of some samples were acquired on a UV-Vis-NIR Cary 5000 spectrophotometer as a courtesy of Agilent Technologies Mexico; we thank Rogelio Garcia for these measurements. We acknowledge the technical support from Adrian Villanueva Luna (CICESE) in the NIR irradiaton setup.

Conflicts of Interest: The authors declare no conflict of interest.

\section{References}

1. Allen, C.; Maysinger, D.; Eisenberg, A. Nano-engineering block copolymer aggregates for drug delivery. Colloids Surf. B. 1999, 16, 3-27. [CrossRef]

2. Jones, M.C.; Leroux, J.C. Polymeric micelles-a new generation of colloidal drug carriers. Eur. J. Pharm. Biopharm. 1999, 48, 101-111. [CrossRef]

3. Uchegbu, I.F.; Vyas, S.P. Non-ionic surfactant based vesicles (niosomes) in drug delivery. Int.J. Pharm. 1998, 172, 33-70. [CrossRef]

4. Discher, D.E.; Eisenberg, A. Polymer vesicles. Science 2002, 297, 967. [CrossRef] [PubMed]

5. Ayen, W.Y.; Garkhal, K.; Kumar, N. Doxorubicin-loaded (PEG)3-PLA nano-polymersomes: Effect of solvents and process parameters on formulation development and in vitro study. Mol. Pharmaceutics 2011, 8, 466-478. [CrossRef]

6. Ayen, W.Y.; Garkhal, K.; Kumar, N.A. Systematic study on lyophilization process of polymersomes for long-term storage using doxorubicin-loaded (PEG)3-PLA nanopolymersomes. Eur. J. Pharm. Sci. 2012, 46, 405-414. [CrossRef]

7. Hu, X.; Zhang, Y.; Xie, Z.; Jing, X.; Belloti, A.; Gu, Z. Stimuli-responsive polymersomes for biomedical applications. Biomacromolecules 2017, 18, 649-673. [CrossRef]

8. Yildirim, T.; Traeger, A.; Sungur, P.; Hoeppener, S.; Kellner, C.; Yildirim, I.; Pretzel, D.; Schubert, S.; Schubert, U.S. Polymersomes with endosomal $\mathrm{pH}$-induced vesicle-to-micelle morphology transition and a potential application for controlled Doxorubicin delivery. Biomacromolecules 2017, 18, 3280-3290. [CrossRef] 
9. Gatish, J.; Huang, X.; Voit, B. Engineering functional polymer capsules toward smart nanoreactors. Chem. Rev. 2016, 116, 1053-1093.

10. Warren, N.J.; Armes, S.P.; Mykhaylyk, O.O.; Mahmood, D.; Ryan, A.J. RAFT aqueous dispersion polymerization yields poly(ethylene glycol)-based diblock copolymer nano-objects with predictable single phase morphologies. J. Am. Chem. Soc. 2014, 136, 10174-10185. [CrossRef] [PubMed]

11. Touve, M.A.; Figg, C.A.; Wright, D.B.; Park, C.; Cantlon, J.; Sumerlin, B.S.; Gianneschi, N.C. Polymerization-induced self-assembly of micelles observed by liquid cell transmission electron microscopy. Macromolecules 2017, 50, 935-943. [CrossRef] [PubMed]

12. Sanson, C.; Schatz, C.; Le Meins, J.F.; Brulet, A.; Soum, A.; Lecommandoux, S. Biocompatible and biodegradable poly(trimethylene carbonate)-b-poly (L-glutamic acid) polymersomes: Size control and stability. Langmuir 2010, 26, 2751-2760. [CrossRef]

13. Schmalz, A.; Hanisch, M.; Schmalz, H.; Müller, A.H. Double stimuli-responsive behavior of linear and star-shaped poly( $N, N$-diethylaminoethyl methacrylate) in aqueous solution. Polymer 2010, 51, 1213-1217. [CrossRef]

14. Tan, J.F.; Ravi, P.; Too, H.P.; Hatton, T.A.; Tam, K.C. Association behavior of biotinylated and non-biotinylated poly(ethylene oxide)-b-poly(2 (diethylamino)ethyl methacrylate). Biomacromolecules 2005, 6, 498-506. [CrossRef] [PubMed]

15. Xu, X.; Liu, C.; Huang, J. Synthesis, characterization, and stimuli-sensitive properties of triblock copolymer poly(ethylene oxide)- $b$-poly(2-(diethylamino)ethyl methacrylate)-b-poly( $N$-isopropylacrylamide). J. Appl. Polym. Sci. 2008, 108, 2180-2188. [CrossRef]

16. Faraha, S.; Aviva, O.; Laoutb, N.; Ratnerb, S.; Beythc, N.; Domba, A.J. Quaternary ammonium poly(diethylaminoethyl methacrylate) possessing antimicrobial activity. Colloids Surf. B. 2015, 128, 608-613. [CrossRef]

17. Cortez-Lemus, N.A.; Garcia-Soria, S.V.; Paraguay-Delgado, F.; Licea-Claverie, A. Synthesis of gold nanoparticles using poly (ethyleneglycol)-b-poly ( $N, N$-diethylaminoethylmethacrylate) as nanoreactors. Polym. Bull. 2017, 74, 3527-3544. [CrossRef]

18. Muddineti, O.S.; Ghosh, B.; Biswas, S. Current trends in using polymer coated gold nanoparticles for cancer therapy. Int. J. Pharm. 2015, 484, 252-267. [CrossRef]

19. Sheng, W.; He, S.; Seare, W.J.; Almutairi, A. Review of the progress toward achieving heat confinement-the holy grail of photothermal therapy. J. Biomed. Opt. 2017, 22, 080901. [CrossRef] [PubMed]

20. Haine, A.T.; Niidome, T. Gold nanorods as nanodevices for bioimaging, photothermal therapeutics, and drug delivery. Chem. Pharm. Bull. (Tokyo) 2017, 65, 625-628. [CrossRef]

21. Sun, Q.; He, F.; Bi, H.; Wang, Z.; Sun, C.; Li, C.; Xu, J.; Yang, D.; Wang, X.; Gai, S.; Yang, P. An intelligent nanoplatform for simultaneously controlled chemo-, photothermal, and photodynamic therapies mediated by a single NIR light. Chem. Eng. J. 2019, 362, 679-691. [CrossRef]

22. Chen, W.H.; Xu, X.D.; Jia, H.Z.; Lei, Q.; Luo, G.F.; Cheng, S.X.; Zhuo, R.X.; Zhang, X.Z. Therapeutic nanomedicine based on dual-intelligent functionalized gold nanoparticles for cancer imaging and therapy in vivo. Biomaterials 2013, 34, 8798-8807. [CrossRef]

23. Liao, J.; Li, W.; Peng, J.; Yang, Q.; Wei, Y.; Zhang, X.; Qian, Z. Combined cancer photothermal-chemotherapy based on Doxorubicin/gold nanorod-loaded polymersomes. Theranostics 2015, 5, 345-356. [CrossRef]

24. Liu, J.; Detrembleur, C.; De Pauw-Gillet, M.C.; Mornet, S.; Duget, E.; Jérôme, C. Gold nanorods coated with a thermo-responsive poly(ethylene glycol)- $b$-poly( $N$-vinylcaprolactam) corona as drug delivery systems for remotely near infrared-triggered release. Polym. Chem. 2014, 5, 799-813. [CrossRef]

25. Zhong, Y.; Wang, C.; Cheng, L.; Meng, F.; Zhong, Z.; Liu, Z. Gold nanorod-cored biodegradable micelles as a robust and remotely controllable Doxorubicin release system for potent inhibition of drug-sensitive and -resistant cancer cells. Biomacromolecules 2013, 14, 2411-2419. [CrossRef]

26. Gole, A.; Murphy, C. Seed-mediated synthesis of gold nanorods: Role of the size and nature of the seed. Chem. Mater. 2004, 16, 3633-3640. [CrossRef]

27. Knights, O.B.; McLaughlan, J.R. Gold nanorods for light-based lung cancer theranostics. Int. J. Mol. Sci. 2018, 19, 3318. [CrossRef]

28. Xiao, Y.; Hong, H.; Matson, V.Z.; Javadi, A.; Xu, W.; Yang, Y.; Zhang, Y.; Engle, J.W.; Nickles, R.J.; Cai, W.; Steeber, D.A.; Gong, S. Gold nanorods conjugated with doxorubicin and cRGD for combined anticancer drug delivery and PET imaging. Theranostics 2012, 2, 757-768. [CrossRef] 
29. Mirza, A.Z. A novel drug delivery system of gold nanorods with doxorubicin and study of drug release by single molecule spectroscopy. J. Drug Targeting 2015, 23, 52-58. [CrossRef]

30. Gole, A.; Murphy, C. Polyelectrolyte-coated gold nanorods: Synthesis, characterization and immobilization. Chem. Mater. 2005, 17, 1325-1330. [CrossRef]

31. Sason, C.; Schatz, C.; Le Meins, J.; Soum, A.; Thévenot, J.; Garanger, E.; Lecommanadoux, S. A simple method to achieve high doxorubicin loading in biodegradable polymersomes. J. Control. Release 2010, 147, 428-435. [CrossRef]

32. Navarro-Vega, P.; Zizumbo-Lopez, A.; Licea-Claverie, A.; Vega-Rios, A.; Paraguay-Delgado, F. Equilibrium and nonequilibrium nanoscale ordering of polystyrene- $b$-poly $(N, N$-diethylaminoethyl methacrylate), a block copolymer carrying tertiary amine functional groups. J. Nanomater. 2014, 2014, 725356. [CrossRef]

33. Zhang, G.; Ge, Z.; Liu, S.; Hu, J. Stimuli-responsive tertiary amine methacrylate-based blockcopolymers: Synthesis, supramolecular self-assembly and functional applications. Prog. Polym. Sci. 2014, 39, 1096-1143.

34. Lee, H.; Venable, R.M.; MacKerell, A.D., Jr.; Pastor, R.W. Molecular dynamics studies of polyethylene oxide and polyethylene glycol: Hydrodynamic radius and shape anisotropy. Biophys J. 2008, 95, 1590-1599. [CrossRef]

35. Zhang, Q.; Weber, C.; Schubert, U.S.; Hoogenboom, R. Thermoresponsive polymers with lower critical solution temperature: From fundamental aspects and measuring to recommended turbidimetry conditions. Mater. Horiz. 2017, 4, 109-116. [CrossRef]

36. Salgado-Rodríguez, R.; Licea-Claverie, A.; Arndt, K.F. Random copolymers of N-Isopropylacrylamide and methacrylic acid monomers with hydrophobic spacers: $\mathrm{pH}$-tunable temperature sensitive materials. Eur. Polym. J. 2004, 40, 1066-7857.

37. Pikabea, A.; Ramos, J.; Forcada, J. Production of cationic nanogels with potential use in controlled drug delivery. Part. Part. Syst. Charact. 2014, 31, 101-109. [CrossRef]

38. Burrows, N.D.; Lin, W.; Hinman, J.G.; Dennison, J.M.; Vartanian, A.M.; Abadeer, N.S.; Grzincic, E.M.; Jacob, L.M.; Li, J.; Murphy, C.J. Surface Chemistry of Gold Nanorods. Langmuir 2016, 32, 9905-9921. [CrossRef] [PubMed]

39. Huff, T.B.; Tong, L.; Zhao, Y.; Hansen, M.N.; Cheng, J.; Wei, A. Hyperthermic effects of gold nanorods on tumor cells. Nanomedicine 2007, 2, 125-132. [CrossRef]

40. Dickerson, E.B.; Dreaden, E.C.; Huang, X.; El-Sayed, I.H.; Chu, H.; Pushpaketh, S.; McDonald, J.F.; El-Sayed, M.A. Gold nanorods assisted near-infrared plasmonic photothermal therapy (PPTT) of squamous cell carcinoma in mice. Cancer Lett. 2008, 269, 57-66. [CrossRef]

41. Sanchis, A.; Salvador, J.P.; Marco, M.P. Light-induced mechanisms for nanocarriers cargo release. Colloids Surf. B 2019, 173, 825-832. [CrossRef] [PubMed]

42. Wang, J.; Han, J.; Zhu, C.; Xi, J.; Fan, L.; Guo, R. GNRs/PPy/m-SiO 2 Core/Shell hybrids as drug nanocarriers for efficient chemo-photothermal therapy. Langmuir 2018, 34, 14661-14669. [CrossRef]

43. Chen, J.; Li, X.; Zhao, X.; Wu, Q.; Zhu, H.; Mao, Z.; Gao, C. Doxorubicin-conjugated pH-responsive gold nanorods for combined photothermal therapy and chemotherapy of cancer. Bioact. Mater. 2018, 3, 347-354. [CrossRef] [PubMed]

44. Messager, L.; Gaitzsch, J.; Chierico, L.; Battalia, G. Novel aspects of encapsulation and delivery using polymersomes. Curr. Opin. Pharmacol. 2014, 18, 104-108. [CrossRef]

45. Gallois, L.; Fiallo, M.; Garnier-Suillerot, A. Comparison of interaction of doxorubicin, daunorubicin, idarubicin and idarubicinol with large unilamellar vesicles circular dischroism study. Biochim. Biophys. Acta 1998, 1370, 31-40. [CrossRef]

46. Chen, W.; Du, J.Z. Ultrasound and $\mathrm{pH}$ dually responsive polymer vesicles for anticancer drug delivery. Sci. Rep. 2013, 3, 2162. [CrossRef]

47. Kumar-Kankala, R.; Liu, C.-G.; Chen, A.-Z.; Wang, S.-B.; Xu, P.-Y.; Kumar-Mende, L.; Liu, C.-L.; Lee, C.-H.; $\mathrm{Hu}$, Y.-F. Overcoming Multidrug Resistance through the Synergistic Effects of Hierarchical pH-Sensitive, ROS-Generating Nanoreactors. ACS Biomater. Sci. Eng. 2017, 3, 2431-2442. [CrossRef] 
48. Kumar-Kankala, R.; Tsai, P.-Y.; Kuthati, Y.; Wei, P.-R.; Liu, C.-L.; Lee, C.-H. Overcoming multidrug resistance through co-delivery of ROS-generating nano-machinery in cancer therapeutics. J. Mater. Chem. B 2017, 5, 1507-1517. [CrossRef]

49. Chen, Y.; Cheng, Y.; Zhao, P.; Zhang, S.; Li, M.; He, C.; Zhang, X.; Yang, T.; Yan, R.; Ye, P.; Ma, X.; Xiang, G. Co-delivery of doxorubicin and imatinib by $\mathrm{pH}$ sensitive cleavable PEGylated nanoliposomes with folate-mediated targeting to overcome multidrug resistance. Int. J. Pharm. 2018, 542, 266-279. [CrossRef] [PubMed]

(C) 2019 by the authors. Licensee MDPI, Basel, Switzerland. This article is an open access article distributed under the terms and conditions of the Creative Commons Attribution (CC BY) license (http://creativecommons.org/licenses/by/4.0/). 